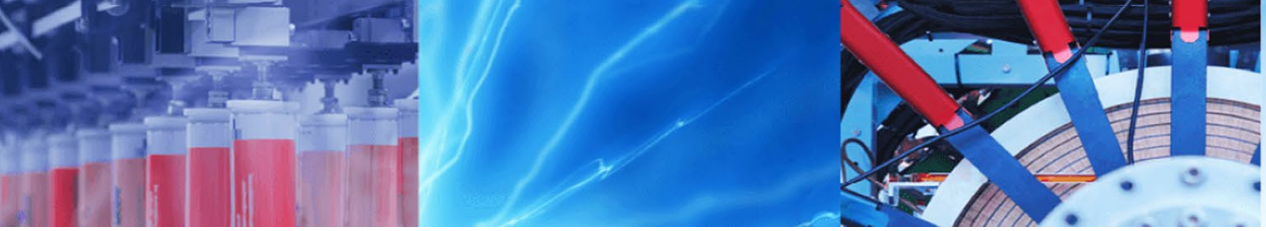

Research Article

\title{
Conceptual DFT study of the chemical reactivity of four natural products with anti-sickling activity
}

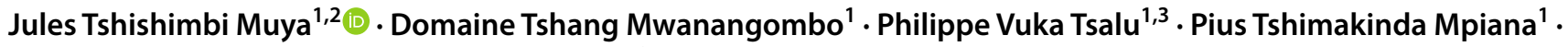 \\ Damien Sha-Tshibey Tshibangu ${ }^{1} \cdot$ Hoeil Chung ${ }^{2}$
}

(c) Springer Nature Switzerland AG 2019

\begin{abstract}
Theoretical reactivity indices based on the conceptual density functional theory were computed to investigate the reactivity of four anti-sickling plant-isolated terpenes: betulinic acid, betulinic acid acetate, friedelan-3-one, and ursolic acid. Herein, global reactivity indices such as the HOMO energy, electronic chemical potential, hardness, and electrophilicity and the local reactivity descriptors like Fukui functions, dual descriptors, and molecular electrostatic potentials for the anti-sickling agents are discussed. The binding energies of water on the most active site are in between -19 and $-6 \mathrm{kcal} /$ mol at B3LYP/6-31G (d). A molecular docking of anti-sickling agents and deoxyhemoglobin including binding energies, hydrogen bond distances and pictorial representation of viable docked poses revealed that betulinic acid and ursolic acid are the most potent molecules with a common binding site.
\end{abstract}

Keywords Sickle cell · Conceptual density functional theory $\cdot$ M062X $\cdot$ B3LYP $\cdot$ Chemical reactivity $\cdot$ Docking

\section{Introduction}

Sickle cell disease (SCD), commonly known as sickle cell anemia or drepanocytosis, is a group of genetic disorders that affect the hemoglobin $(\mathrm{Hb})$ in its sixth position of the $\beta$-globin chain [1-5]. SCD starts as a result of a single nucleotide mutation triggered by the replacement of a polar amino acid (glutamic acid) by a less polar one (valine) $[2,3]$. This genetically initiated mutation is characterized by a drastic modification of the affinity of $\beta$-globin to oxygen, which yields the formation of a less soluble hydrophobic abnormal $\mathrm{Hb}$, called $\mathrm{S}$ hemoglobin (denoted as $\mathrm{Hb} \mathrm{SS}$ ) [1-3]. The formation of $\mathrm{Hb}$ SS in the condition in which a region of the body is deprived of adequate oxygen supply at the tissue level (hypoxia) leads to an intracellular aggregation of the atypical $\mathrm{Hb} \mathrm{SS}$, which is responsible for the sickling effects of erythrocytes, as well as all deadly symptoms exhibited by sicklers. Sickle disease can lead to iron deficiency anemia [6] accompanying various symptoms such as shortness of breath, fatigue, and delayed in growth of children. Sicklers'tissues and organs deprived of oxygen-rich blood can lead to organs damage, especially in lungs, kidneys, spleen and brain $[1,3,7]$.

Tremendous efforts have been made to manage and cope $S C D$, enabling several children born with $S C D$ to survive [7]. Currently used drugs to treat sickle cell disease including transfusion of cells cannot decrease the amount of $\mathrm{Hb} \mathrm{S}$ in the bloodstream to zero and fully cure sicklers $[1,3]$. However, population with low income are still not able to have access to the medication. It was reported that Africa possesses the major affected patients estimated to be about 50 millions $[3,4]$. Nowadays, bone marrow

Electronic supplementary material The online version of this article (https://doi.org/10.1007/s42452-019-1438-8) contains supplementary material, which is available to authorized users.

Jules Tshishimbi Muya, Julescmuya.tmuya@gmail.com; Hoeil Chung, hoeil@hanyang.ac.kr| Department of Chemistry, University of Kinshasa, Kinshasa 190, Democratic Republic of the Congo. ${ }^{2}$ Department of Chemistry, Hanyang University, Seoul, South Korea. ${ }^{3}$ Department of Chemistry, University of Ulsan, Ulsan, South Korea. 
transplant, also known as stem cell transplant, is mostly considered as potential cure for sickle cell anemia [8-13]. Stem cell transplant from a compatible donor was found more recently to be successful for sicklers patients becoming SCD-free after treatment [8-10]. The donated marrow takes over the production of the patient's red blood cells, and the amount of $\mathrm{Hb}$ SS in the bloodstream can almost decrease to zero. However, complications on this treatment could do more harm than good on patients $[1,8]$. Unfortunately, the latter is only applicable for younger sickler and requires a compatible donor of the marrow [1].

Chemicals derived from medicinal plants have great potential to treat many diseases and are widely investigated for diverse health issues [4, 14-16]. Our previous works [5, 17-22] have led to the identification of various bioactive agents against SCD from plants including betulinic acid $(\mathbf{A})$, betulinic acid acetate $(\mathbf{B})$, friedelan-3-one (C), and ursolic acid (E), whereas the isolated $\beta$-sitosterol (D) was found to be inactive (Fig. 1a-e). In addition, Ayaz et al. [23] revealed that $\beta$-sitosterol is a potential compound for the management of memory deficit disorders including Alzheimer's disease. Besides the anti-sickling effects, isolated triterpenes are also known for their various biological properties, including anti-trypanosomiasis, anti-microbial, and anti-HIV [24-26]. Betulinic acid (A) has been found to present antiretroviral, antimalarial, anticancer and anti-inflammatory properties as well as antisickling agent [27-31]. It is worth noticing that the discovery of the bio-activity of betulinic acid against sickle disease was awarded a patent [USPTO/8685469]. Tshilanda et al. [32] investigated the anti-sickling activity of ursolic acid (E) isolated from 0 . gratissimum plant. Mpiana et al. [33] reported the anti-sickling activities observed in some extracts of triterpenoids agent medicinal plants isolated from Callistemon Viminalis, Melaleuca Bracteata Var, Revolution Gold Syzygium Guineense and Syzygium Cordatum. Similar to SCD-101 botanical drug [34] with in vitro and in vivo-anti-sickling activity, the mechanism by which betulinic acid (A), betulinic acid acetate (B), friedelan-3-one (C), and ursolic acid (E) inhibit sickling is also unknown.

Very few theoretical studies have been performed on betulinic acid and its derivatives (betulinic acid acetate, friedelan-3-one, and ursolic acid). As far we know, Malleda et al. [35] studied the interaction of betulinic acid (A) with human serum albumin using molecular docking and molecular dynamic simulation methods and found that betulinic acid can bind in the large hydrophobic cavity of drug binding site by hydrophobic and hydrogen bond interactions, in which several cyclohexyl groups of $\mathbf{A}$ were interacting with Phe-206, Arg-209, Ala-210, Ala-213, Leu327, Gly-328, Leu-331, Ala-350, and Lys-351 residues by hydrophobic interactions. Also, $\mathrm{H}$-bonds were formed between O-H of A with Phe-206 and Glu-354 of human serum albumin of 2.4 and 2.8 Á. More recently, Kan et al. [36] have computed some DFT descriptors of $\boldsymbol{A}$ and carried out docking calculations with phospholipase A2 (PLA2) to shed light on its anti-inflammatory properties. The authors found that based on DFT reactivity descriptors (e.g., hardness, chemical potential, electrophilicity, softness, polarizability), the betulinic acid (A) is kinetically more reactive in water and its solubility is to be increased in non-polar solvents $(-9.98 \mathrm{kcal} / \mathrm{mol}$ in water vs. $-14.38 \mathrm{kcal} / \mathrm{mol}$ in carbon tetrachloride) and with increasing $\mathrm{pH}$. The betulinic acid was found to be mutagenic compound but noncarcinogenic. The docking study of $\mathbf{A}$ with PLA2 predicted interactions of $\mathbf{A}$ with Gly-22 and Gly-29 through $\mathrm{H}$-bonds and Leu-2, Phe-5, His-6, Ala-17, Ala-18, His-47, and Tyr-51 through different types of hydrophobic interactions. The binding affinity of $\mathbf{A}$ was $-9.81 \mathrm{kcal} / \mathrm{mol}$ which is comparable to the binding affinity of potent inhibitor 6-phenyl-4(R)-(7-phenyl-heptanoylamino)-hexanoic acid (BR4) $(-8.11 \mathrm{kcal} / \mathrm{mol})$.

However, despite the prominent impact that these molecular drugs have on SCD, there is still lack of theoretical research on sickle cell disease. To the best of our knowledge, there have been no theoretical comparative studies reported on the interaction between human hemoglobin and betulinic acid (A), betulinic acid acetate (B), friedelan3-one (C), $\beta$-sitosterol (D), and ursolic acid (E). In addition, the active site of these isolated anti-sickling molecules (A-E) with hemoglobin is still unknown which makes difficult the evaluation of their bioactivity using molecular docking studies. The identification of the active site of these anti-sickling molecules will make easier their bioactivity investigation. These molecules possess carbonyl, hydroxyl, and carbon-carbon $\pi$-bonds which are susceptible to interact with nucleophilic and electrophilic agents. The knowledge of the chemical reactivity descriptors of anti-sickling molecules is essential for a better understanding of their chemical interactions toward organism receptors operating during their reaction mechanisms $[37,38]$. In this regard, since the action mode of betulinic acid (A), betulinic acid acetate (B), friedelan-3-one (C), and ursolic acid (E) implying interactions between active principles and receptor sites is unknown, a study on their molecular responses toward electrophilic and nucleophilic attacks appears to be important. As continuation of our SCD project, in the present work, the activity of $\mathbf{A}-\mathbf{E}$ molecules is addressed with global and local reactivity descriptors undergrounded in conceptual density functional theory $[37,38]$. Further, the interactions of the anti-sickling plantisolated terpenes (A-E) with the deoxyhemoglobin (PDB entry 2HHB) [39] are investigated using molecular docking method. The docking calculations results include binding energy $(\mathrm{kcal} / \mathrm{mol})$, hydrogen bond distances, and pictorial representation of viable docked poses. 


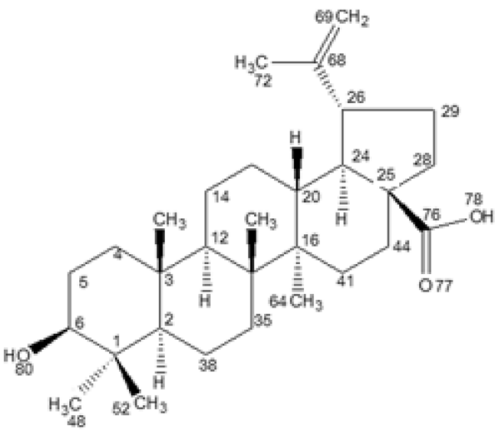

(a) Betulinic acid (A)

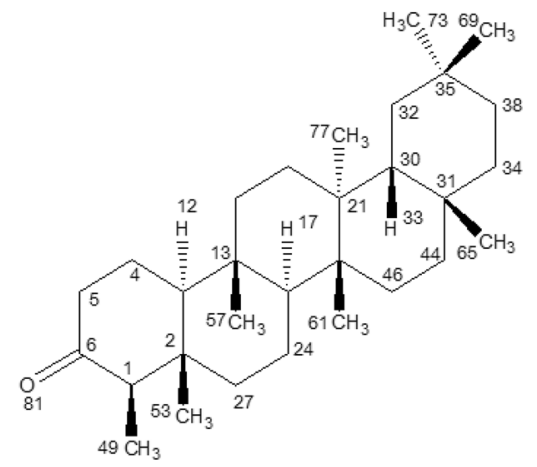

(c) Friedelan-3-one (C)

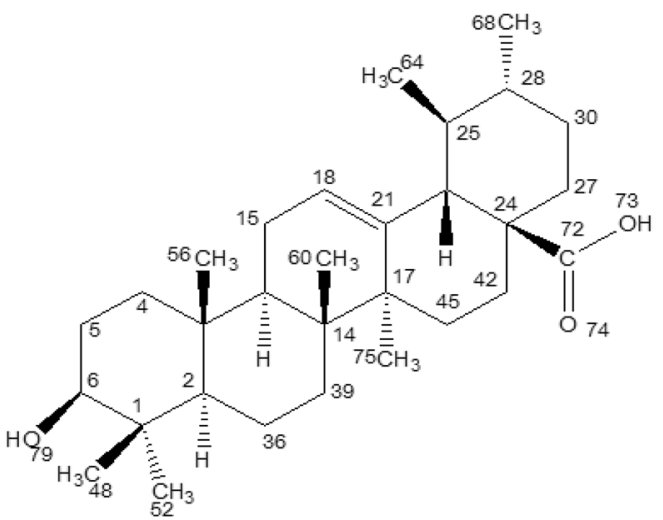

(e) Ursolic acid (E)

Fig. 1 Structures and labels of molecules studied in the present paper

This paper is structured as follows:

- Firstly, the global reactivity descriptors (e.g., hardness $(\eta)$, chemical potential $(\mu=-\chi)$, softness (S), electronegativity $(\chi)$, and electrophilicity $(\omega)$ in $\mathrm{eV}$ and dipole moment in Debye and polarizability) of

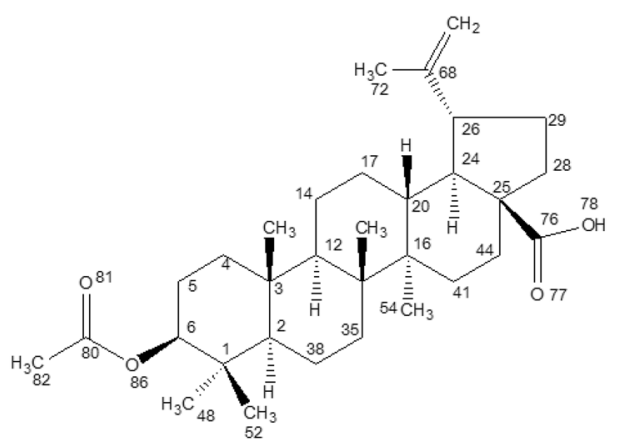

(b) Betulinic acid acetate (B)

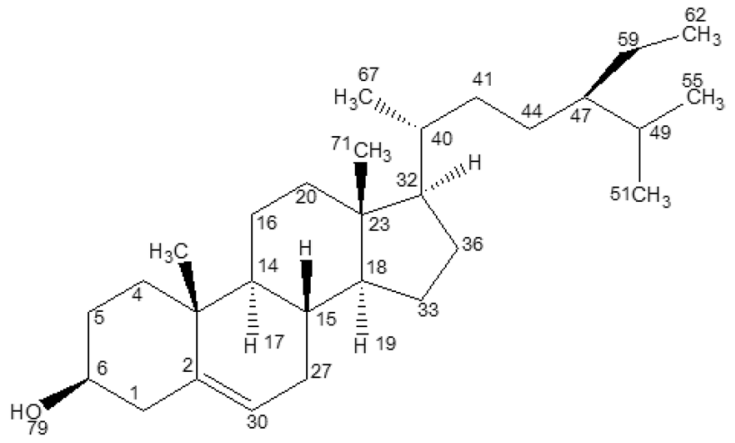

(d) $\beta$-Sitosterol (D) betulinic acid (A), betulinic acid acetate (B), friedelan3-one (C), $\beta$-sitosterol (D), and ursolic acid (E) are compared at B3LYP and M062X levels using $6-31 \mathrm{G}(d)$ and $6-311+\mathrm{G}(d, p)$ basis sets in gas phase. These molecules are found to act as electron donors and present similar molecular properties to valine and glutamic acid. 
- Secondly, local reactivity descriptors (molecular electrostatic potentials denoted as MEP, Fukui functions, and dual descriptors) were computed to figure out the most active sites toward electrophilic and nucleophilic agents. Fukui functions, MEPs, and dual maps point out the carbonyl and carbon-carbon $\pi$-bonds as preferred active sites for electrophilic attacks.

- Thirdly, the interactions of A-E with water were computed to probe the reactive sites predictions and to check the strength of $\mathrm{H}$-bonds interactions. The calculations reveal that water binds strongly with $A$ $(\mathrm{BE}=-18.87 \mathrm{kcal} / \mathrm{mol}), \mathrm{B}(\mathrm{BE}=-12.64 \mathrm{kcal} / \mathrm{mol})$, and $\mathrm{E}$ $(-12.51 \mathrm{kcal} / \mathrm{mol})$ compared to $C(B E=-5.62 \mathrm{kcal} / \mathrm{mol})$ and $\mathrm{D}(\mathrm{BE}=-5.93 \mathrm{kcal} / \mathrm{mol})$.

- Fourthly, the binding poses of the A-E ligands were predicted in the beta deoxyhemoglobin (PDB entry 2HHB) and compared with 1NIH_B crystal structure comprising an allosteric ligand effector, inositol hexaphosphate ligand (IHP). This docking analysis of the interaction of $A-E$ in the hemoglobin environment suggests a considerable hydrogen bond formation between ligands and the amino acids residues arginine, valine, lysine, and tyrosine. The interactions between $\mathrm{A}-\mathrm{E}$ and $2 \mathrm{HHB}$ were found to increase in the following order: $C(-7.86 \mathrm{kcal} /$ $\mathrm{mol})<\mathrm{D}(-8.15 \mathrm{kcal} / \mathrm{mol})<\mathrm{B}(-8.39 \mathrm{kcal} / \mathrm{mol})<\mathrm{E}$ $(-9.10 \mathrm{kcal} / \mathrm{mol})<\mathrm{A}(-9.32 \mathrm{kcal} / \mathrm{mol})$.

We show through the present study that the HOMO, chemical potential, dipole moment, and electrophilicity of $\mathbf{A}-\mathbf{C}$ and $\mathbf{E}$ can have an influence on their bioactivities and these A-E molecules behave as electron donors with preferential active sites presumably located on carbonyl. The water interaction energies and the hemoglobin interactions suggest $\mathbf{A}$ to be more stabilized in both water and hemoglobin environment media. The analysis of the docking results revealed that $\mathbf{A}$ and $\mathbf{E}$ interact with $2 \mathrm{HHB}$ on a common binding site with the amino acid residues Arg104, while B, C, D, and IHP show different binding sites.

\section{Computational methods}

The geometries of betulinic acid $(\mathbf{A})$, betulinic acid acetate (B), friedelan-3-one (C), $\beta$-sitosterol (D), and ursolic acid (E) were optimized at B3LYP [40] and M062X [41] with 6-31G $(d)$ and $6-311+\mathrm{G}(d, p)$ basis sets [42]. The free energies of solvation were computed using the continuum solvation model based on density (SMD) [43] and polarizable continuum model (PCM) [44] at M062X/6-31G(d) implemented in Gaussian 16B01 [45]. Vibrational calculations were performed to ensure that optimized geometries are true minima. The C40-C41-C44-C47 dihedral angle of $\beta$-sitosterol was scanned to identify the global minimum (Figure S1a-b).

The root-mean-square deviation of atomic positions (RMSD) between the B3LYP optimized geometry obtained after scan of the (C40-C41-C44-C47) dihedral angle and the equilibrium geometry from MD trajectory drawn by VEGAZZ was found around 1.6 angstrom (Figure S1c). The difference in the (C40-C41-C44-C47) dihedral angle between the two geometries was small, nearly $2.46^{\circ}$.

The chemical potential $(\mu)$, hardness $(\eta)$, and electrophilicity $(\omega)$ were computed to get insight into the global reactivity of $\mathbf{A}-\mathbf{E}$ molecules. These global descriptors were computed using the following formula [37, 38, 46-49]:

$\mu=-1 / 2\left(\varepsilon_{\mathrm{L}}+\varepsilon_{\mathrm{H}}\right)$

$\eta \approx\left(\varepsilon_{\mathrm{L}}-\varepsilon_{\mathrm{H}}\right)$

$\omega=\left(\varepsilon_{\mathrm{L}}+\varepsilon_{\mathrm{H}}\right)^{2} / 2\left(\varepsilon_{\mathrm{L}}-\varepsilon_{\mathrm{H}}\right)$

The chemical potential measures the escaping tendency of electron from equilibrium, while the hardness measures the resistance of molecular system to charge transfer [49]. The electrophilicity describes the stabilization energy of the molecular system when saturated by electrons from the surrounding. The electron-donating and electron-accepting powers are calculated by [46-48]:

$\omega^{-}=(3 I+A)^{2} / 16(I-A)$

$\omega^{+}=(I+3 A)^{2} / 16(I-A)$

The net electrophilicity $(\Delta \omega)$ was estimated as a sum of electron-donating and electron-accepting powers.

The Fukui functions $\left(f^{+}(r)\right.$ and $\left.f^{-}(r)\right)$, and the molecular electrostatic potentials (MEP) $[37,48]$ were computed as local reactivity descriptors of A-E. A descriptor derived from Fukui function positive $\left(f^{+}(r)\right)$ and Fukui function negative $\left(f^{-}(r)\right)$ called dual descriptor $(\Delta f(r))$ was also employed [50]:

$\Delta f(r)=f^{+}(r)-f^{-}(r)=\rho(r)_{N+1}-2 \rho(r)_{N}+\rho(r)_{N-1}$

where $f^{+}(r)$ is estimated, respectively, as the electron density difference for the anion $\left(\rho(r)_{N+1}\right)$ and neutral system $\left(\rho(r)_{N}\right)$ bearing $N+1$ and $N$ electrons, and $f^{-}(r)$ the electron density difference between the neutral and the cation system $\left(\rho(r)_{N-1}\right)$ bearing $\mathrm{N}-1$ electrons.

The dual and Fukui functions were computed at $\mathrm{B} 3 \mathrm{LYP} / 6-311+\mathrm{G}(d, p)$ using the finite difference approximation, which takes into account the relaxation effects that inner molecular orbitals experience. The importance of diffuse function in basis sets to produce reliable 3D pictures of dual descriptors was pointed out elsewhere [50].

Condensed Fukui functions $\left(f_{k}^{+}\right.$and $\left.f_{k}^{-}\right)$, dual functions $\left(\Delta f_{k}(r)\right)$, and electrophilicities $\left(\Delta \omega_{k}\right)$ were computed using 
Milliken and NBO charges to determine the reactivity of each atom in A-E:

$f_{k}^{+}=q_{k(N+1)}-q_{k(N)}$

$f_{k}^{-}=q_{k(N)}-q_{k(N-1)}$

$\Delta f_{k}(r)=f_{k}^{+}-f_{k}^{-}$

$\Delta \omega_{k}=\left(\omega_{k}^{+}-\omega_{k}^{-}\right)=\omega\left(f_{k}^{+}-f_{k}^{-}\right)=\omega f$

The binding energies between water and anti-sickling molecules were compared at B3LYP and M062X with 6-31G $(d)$ to probe their reactivities similarities and differences. Gaussview 5.0 [51] and ChemDraw 12 [52] were employed for visualization.

It is worth noting that implicit solvation model does not take in account $\mathrm{H}$-bond interactions. Therefore, A-E molecules were also placed in a water box of dimension $[20 \AA$, $20 \AA, 10 \AA ̊$ and were surrounded by up to 89 water molecules. These molecular systems were then optimized using the consistent-valence force field (CVFF) [53] with the polytope simplex algorithm implemented in VEGAZZ program [54] and reoptimized at PM6 on Gaussian program.

The interaction energies (IE) between anti-sickling molecules $(\mathrm{M})$ and $\left(\mathrm{H}_{2} \mathrm{O}\right)_{n=81-89}$ clusters were computed as single-point energy difference between the anti-sickling molecule surrounded by explicit water molecules $\left(\mathrm{M}\left(\mathrm{H}_{2} \mathrm{O}\right)_{n}\right)$ and its constituents as relaxed in $\mathrm{M}\left(\mathrm{H}_{2} \mathrm{O}\right)_{81-89}$ :

$\mathrm{IE}=\mathrm{E}\left[\mathrm{M}\left(\mathrm{H}_{2} \mathrm{O}\right)_{n=81-89}\right]-\left[\mathrm{E}(\mathrm{M})+\mathrm{E}\left(\mathrm{M}\left(\mathrm{H}_{2} \mathrm{O}\right)_{n=81-89}\right)\right]$

The average energy of water-water interaction in $\mathrm{M}\left(\mathrm{H}_{2} \mathrm{O}\right)_{n=81-89}$ is computed by:
AIE $=\left[\mathrm{E}\left(\mathrm{H}_{2} \mathrm{O}\right)_{n=81-89}-n \mathrm{E}\left(\mathrm{H}_{2} \mathrm{O}\right)\right] / n$

Afterward, the binding poses of the A-E ligands were predicted in the beta deoxyhemoglobin (2HHB entry PDB) [38] using SwissDock software $[55,56]$. Hemoglobin $(\mathrm{Hb})$ is the respiratory protein of the red blood cells which carries $\mathrm{O}_{2}$ from the lungs to the tissues and facilitates the return transport of $\mathrm{CO}_{2}$ from the tissues to the lungs. Its understanding is fundamental to understand protein functions. Molecular docking has become an important tool for assisting structure-based drug design. It includes pose prediction and binding energies calculations [57]. Molecular graphics images from molecular docking calculations were produced using the UCSF Chimera package from the Resource for Biocomputing, Visualization, and Informatics at the University of California, San Francisco [58].

\section{Results}

\subsection{Global reactivity descriptors}

Since no IC50 data are available for chosen anti-sickling molecules, appropriate global and local reactivity descriptors are first investigated based on density functional theory and compared with the experimental activities reported by Tshibangu et al. [21] to evaluate their performance. Table 1 lists the values of selected global reactivity descriptors of betulinic acid $(\mathbf{A})$, betulinic acid acetate (B), friedelan-3-one (C), $\beta$-sitosterol (D), and ursolic acid (E) computed at B3LYP and M062X levels with $6-311+\mathrm{G}(d, p)$ basis set. The molecular properties listed in Table 1 are self-explanatory. Overall speaking,
Table 1 Hardness $(\eta)$, chemical potential $(\mu=-\chi)$, softness (S), electronegativity $(\chi)$, and electrophilicity $(\omega)$ in $\mathrm{eV}$ and dipole moment in Debye and polarizability in a.u of betulinic acid $(\mathbf{A})$, betulinic acid acetate (B), friedelan-3-one (C), $\beta$-sitosterol (D), and ursolic acid (E) computed using B3LYP and M062X (in parenthesis) with $6-311+\mathrm{G}(d, p)$ basis and their bioactivity (act)

\begin{tabular}{llllllll}
\hline Prop & A & B & C & D & E & val \\
\hline H & $-7.08(-8.32)$ & $-6.97(-8.47)$ & $-6.63(-8.32)$ & $-6.33(-7.71)$ & $-6.89(-8.25)$ & $-6.87(-7.14)$ & $-6.70(-9.05)$ \\
$\mathrm{L}$ & $-0.63(-0.37)$ & $-0.57(-0.42)$ & $-0.81(-0.33)$ & $-0.42(-0.21)$ & $-0.59(-0.39)$ & $-1.22(0.00)$ & $-1.58(-0.60)$ \\
$\eta$ & $6.44(7.96)$ & $6.10(8.05)$ & $5.82(7.99)$ & $5.91(7.49)$ & $6.31(7.87)$ & $5.65(8.55)$ & $5.55(8.46)$ \\
$\mu$ & $3.85(4.34)$ & $3.77(4.45)$ & $3.72(4.32)$ & $3.37(3.96)$ & $3.74(4.32)$ & $4.05(4.27)$ & $4.36(4.83)$ \\
$\omega$ & $1.15(1.19)$ & $1.16(1.23)$ & $1.19(1.17)$ & $0.96(1.05)$ & $1.11(1.19)$ & $1.45(1.07)$ & $1.71(1.38)$ \\
$\omega^{-}$ & $4.63(5.04)$ & $4.51(5.18)$ & $4.60(5.00)$ & $3.98(4.54)$ & $4.48(5.02)$ & $5.28(4.80)$ & $5.95(5.70)$ \\
$\omega^{+}$ & $0.78(0.70)$ & $0.74(0.74)$ & $0.88(0.68)$ & $0.61(0.58)$ & $0.74(0.70)$ & $1.23(0.53)$ & $1.59(0.87)$ \\
$\Delta \omega$ & $-3.85(-4.34)$ & $-3.77(-4.45)$ & $-3.72(-4.32)$ & $-3.37(-3.96)$ & $-3.74(-4.32)$ & $-4.05(-4.27)$ & $-4.36(-4.83)$ \\
DM & $6.09(6.23)$ & $8.52(8.67)$ & $3.68(3.67)$ & $1.60(1.66)$ & $6.59(6.70)$ & $3.01(3.03)$ & $4.15(2.43)$ \\
Act [21] & +++ & +++ & + & - & +++ & \\
\hline
\end{tabular}

+++ Strongly active (more than $70 \%$ normalization of sickled blood cells)

+Fairly active (10-50\% normalization of sickled blood cells)

-Inactive (less than $10 \%$ of normalization of sickled blood cells) 
the data are quite similar, and nevertheless small difference can be observed. $\mathbf{B}$ and $\mathbf{D}$ have the lowest and highest HOMO. The energies of LUMOs are almost positive and indicate that they are not favorable to receive any additional electron. The HOMO and LUMO maps of these molecules are portrayed in Fig. 2. The LUMOs have anti-bonding character showing that if one wants to bind an extra electron, it will cost to the molecule. From the HOMO and LUMO maps, the electron densities of the frontier molecular orbitals are more concentrated on one six-member ring and peripheral functional groups. These regions are therefore assumed to be chemically active in accordance with the frontier molecular orbital theory. The HOMO-LUMO gaps, orbital view of hardness, computed with B3LYP ranged between 5.82 and $6.44 \mathrm{eV}$, are smaller than those of M062X estimated to be about 7.49-8.05 eV. Compared to hard molecule like $\mathrm{BF}_{3}$ characterized by a hardness of $11.50 \mathrm{eV}$ at the same B3LYP/6$311+\mathrm{G}(d, p)$ level $(\eta=14.40 \mathrm{eV}$ at M062X/6-311+G(d,p) level), these terpenes appear soft and can interact with soft acceptor molecules.

The electronic chemical potential varies between 3.37 and $3.85 \mathrm{eV}$ at B3LYP (3.96-4.45 eV at M062X), and the electrophilicities are in between 0.96 and $1.19 \mathrm{eV}$ at the same B3LYP level (1.05-1.23 eV at M062X) with the lowest chemical potential and electrophilicity attributed to D. The magnitude of electrophilicities shows clearly that these molecules will prefer acting as electron donors ( $\omega^{-}$of 3.98-4.63 V at B3LYP and 4.54-5.18 eV at M062X) rather than electron acceptors $\left(\omega^{+}\right.$of $0.61-0.88 \mathrm{eV}$ at B3LYP and 0.58-0.74 eV at M062X). The dipole moment (DM) varies between 1.60 and $8.52 \mathrm{D}$ at B3LYP (1.66-8.67D at M062X), with $\mathbf{D}$ the least polar. In general, B3LYP computed descriptors of A-E are close to M062X and approach those of valine and glutamic acid. The latter were considered because it was found that the change arising from the mutation in the beta-globin genes causing sickle hemoglobin responsible for sickle cell anemia converts a glutamic acid codon (GAG) into valine codon (GTG) [59]. Our $\mathrm{B} 3 \mathrm{LYP} / 6-311+\mathrm{G}(d, p)$ reactivity descriptors ( $\eta: 6.44, \mathrm{~s}: 0.15$, $\mu: 3.85$, and $\omega: 1.15)$ of $\mathbf{A}$ are approaching the chemical hardness $(\eta)$, softness $(s)$, chemical potential $(\mu)$, and electrophilicity $(\omega)$ data estimated to be about $6.44,0.15,3.09$, and 1.48 by Khan et al. [36]. The global reactivity descriptors computed at B3LYP and M062X with 6-31G $(d)$ basis set are provided in supplemental materials (Table S1).

According to the data presented in Table 1 and Table S1, 6-31G $(d)$ underestimates the chemical potential, electrondonating and electron-accepting powers, and dipole moments and overestimates the hardness, homo-lumo gaps, and electrophilicity with respect to $6-311+\mathrm{G}(d, p)$. Overall, $6-311+G(d, p)$ and $6-31 \mathrm{G}(d)$ show almost the same trend of global reactivity descriptors.
A, B, and $\mathbf{E}$ comprising carboxylic acid terminal functions are interesting, since they exhibit anti-sickling bioactivity. $\mathbf{B}$ is a derivative of $\mathbf{A}$ obtained after substitution of $\mathrm{O}-\mathrm{H}$ group by an acetate group. The fact that $\mathrm{O}-\mathrm{H}$ substitution in $\mathbf{A}$ did not change the activity of the molecule suggests that the active site in $\mathbf{A}, \mathbf{B}$ and $\mathbf{E}$ is probably the carboxylic group. $\mathbf{E}$ contains hydroxyl and carboxylic group as A, but differs by the backbone constituted by different fused polygons and can be useful in the understanding of the role of the skeleton (fused polygons) on the anti-sickling bioactivity. Further, the least active $\mathbf{C}$ contains also carbonyl, while the nonactive $\mathbf{D}$ possesses a hydroxyl group and carbon-carbon $\pi$-bonds, and both molecules do not have carboxyl group.

Most of the molecules studied in the present paper possess carbonyl, hydroxyl, and carbon-carbon $\pi$-bonds as nucleophilic sites. The active site in these molecules is probably the carbonyl. However, the way polygons are fused and the presence of carbon-carbon $\pi$-bonds in $\mathbf{A}$, $\mathbf{B}$, and $\mathbf{E}$ may not influence the anti-sickling activity. The presence of a carbonyl group seems to be important, but not sufficient to warrant anti-sickling activity.

\subsection{Local reactivity descriptors}

To get a glimpse on the local reactivity descriptors like Fukui functions, molecular electrostatic potential (MEP) and dual descriptors were computed. The Fukui functions and MEPs of these bioactive molecules are depicted in Figs. 3 and 4. The sites where the local descriptors have higher values in terms of magnitudes are predicted to be chemically active. As shown by the Fukui function negative, most of the electron density is localized on the carbonyl and carbon-carbon $\pi$-bonds and those sites are predicted to be preferential sites for soft electrophilic attacks. The dual functions of these molecules were also computed and corroborate with Fukui maps at the same B3LYP/6-311+G $(d, p)$ theoretical level (Figure S2), which point out carbon-carbon $\pi$-bonds and carbonyl groups as preferential electron donors sites. According to Martinez-Araya [50], to get reliable 3D plots of dual descriptors, one needs to include diffuse functions in the basis sets. MEPs show oxygen atoms as favorable sites for hard-hard interactions (Fig. 4), mostly the carbonyl (A-C, E) and hydroxyl (D). The condensed Fukui functions $\left(f_{k}^{-}\right)$, condensed dual functions $\left(\Delta f_{k}(r)\right)$, and condensed electrophilicities $\left(\Delta \omega_{k}\right)$ are provided in supplementary materials and corroborate with the Fukui functions, dual functions, and MEPs showing the carbonyl and carbon-carbon $\pi$-bonds as preferred active sites for electrophilic attacks. 
Fig. 2 HOMO (left) and LUMO (right) computed at B3LYP/6-

$31 \mathrm{G}(d)$ with the iso-surface

of 0.02: a, b betulinic acid, $\mathbf{c}$,

$\mathbf{d}$ betulinic acid acetate, $\mathbf{e , ~} \mathbf{f}$

sitosterol, $\mathbf{g}$, $\mathbf{h}$ ursolic acid, and

$\mathbf{i}, \mathbf{j}$ friedelan-3-one

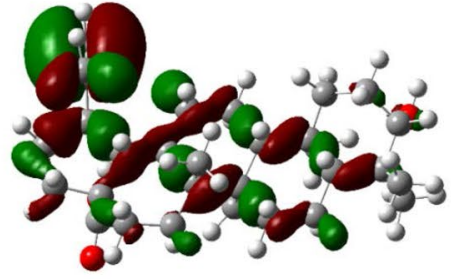

(a)

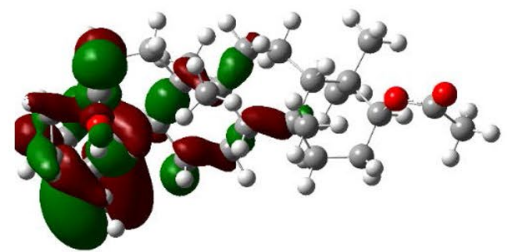

(c)

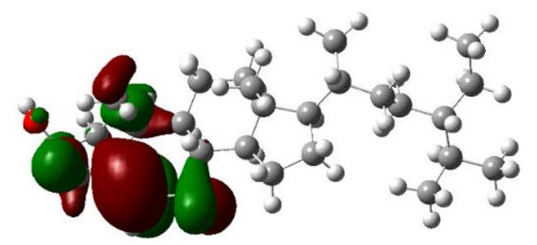

(e)

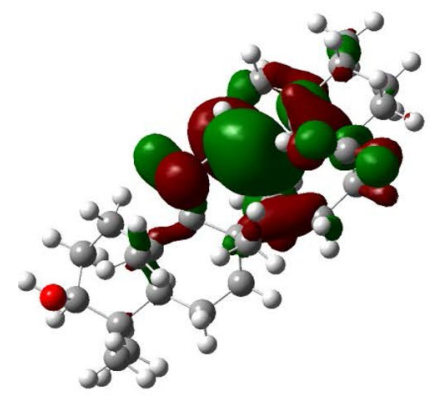

(g)

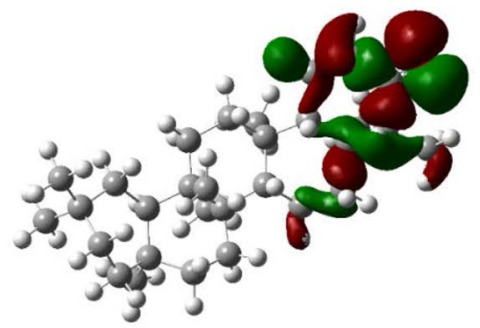

(i)

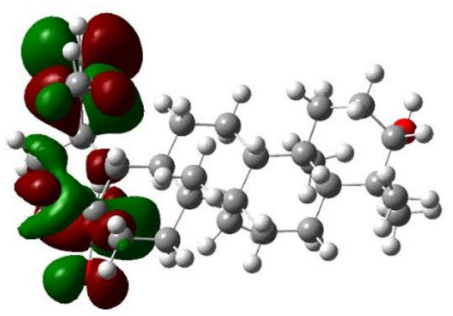

(b)

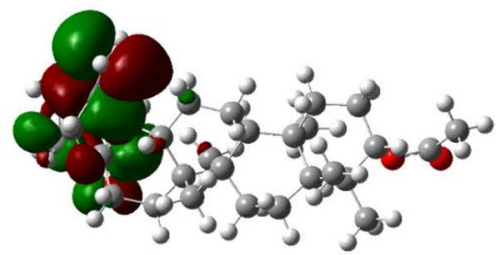

(d)

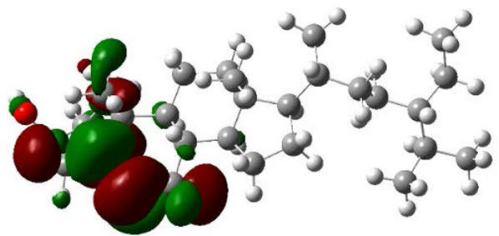

(f)

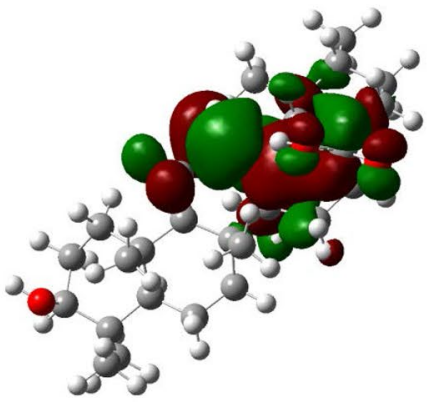

(h)

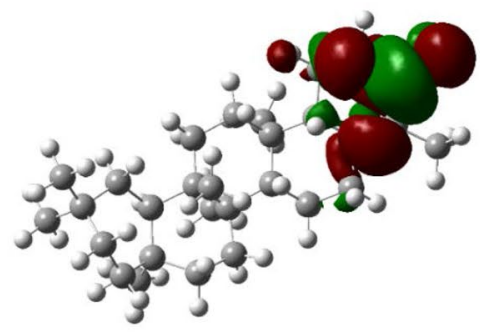

(j) 
Fig. 3 Fukui function negative computed at B3LYP/6$311+\mathrm{G}(d, p)$ of: a betulinic acid, $\mathbf{b}$ betulinic acid acetate, $\mathbf{c}$ sitosterol, $\mathbf{d}$ ursolic acid, and $\mathbf{e}$ friedelan-3-one

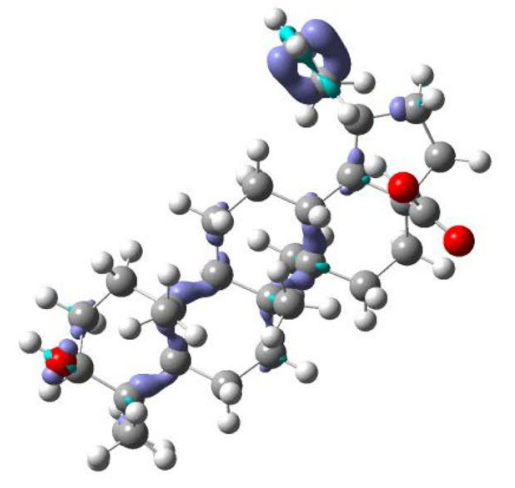

(a)

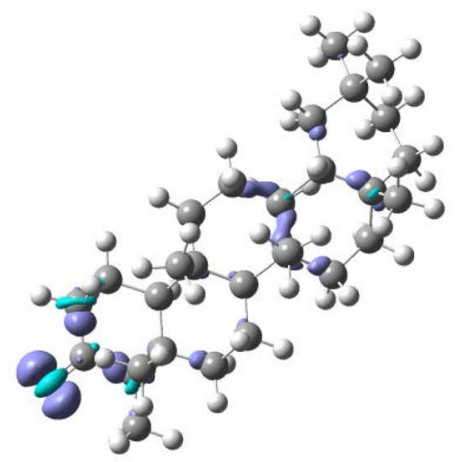

(c)

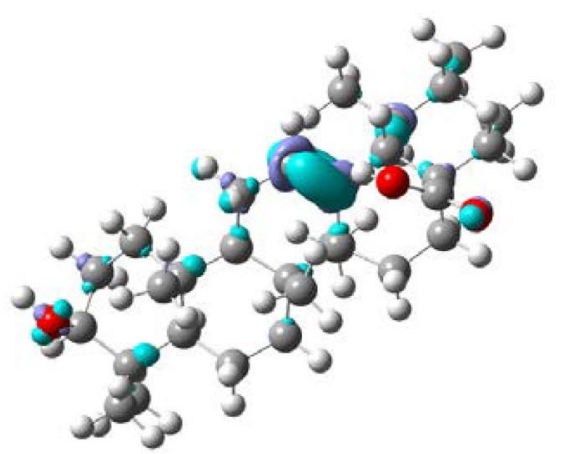

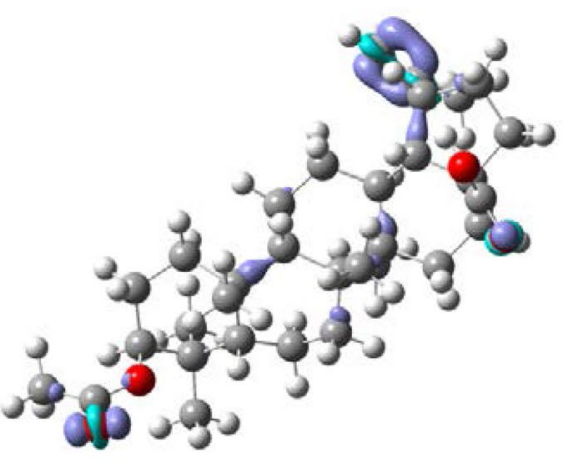

(b)

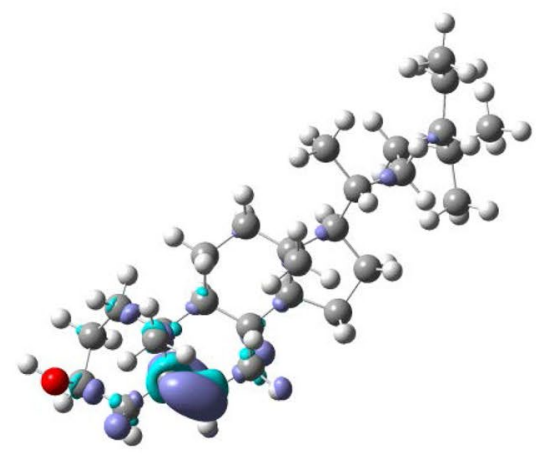

(d)

(e)

\subsection{Interaction energy of A-E with water}

According to global descriptors which suggest those molecules to act as electron donors, only the most active sites susceptible to undergo electrophilic attacks predicted by the MEPs were considered. As water molecule is the most abundant molecule in blood, the former was attached to the oxygen atom site possessing the minimum potential energy to form different complexes with A-E (Fig. 5). Table 2 shows different binding energies of water with A-E computed at B3LYP/6-31G(d). Water binds strongly with $\mathbf{A}(\mathrm{BE}=-18.87 \mathrm{kcal} / \mathrm{mol}), \mathbf{B}(\mathrm{BE}=-12.64 \mathrm{kcal} / \mathrm{mol})$, and $\mathbf{E}(-12.51 \mathrm{kcal} / \mathrm{mol})$ compared to $\mathbf{C}(\mathrm{BE}=-5.62 \mathrm{kcal} /$ $\mathrm{mol})$ and $\mathbf{D}(\mathrm{BE}=-5.93 \mathrm{kcal} / \mathrm{mol})$. The donor-acceptor 
Fig. 4 Molecular electrostatic potentials maps of $\mathbf{A}$ betulinic acid, B ursolic acid acetate, C friedelan-3-one, D sitosterol, E ursolic acid
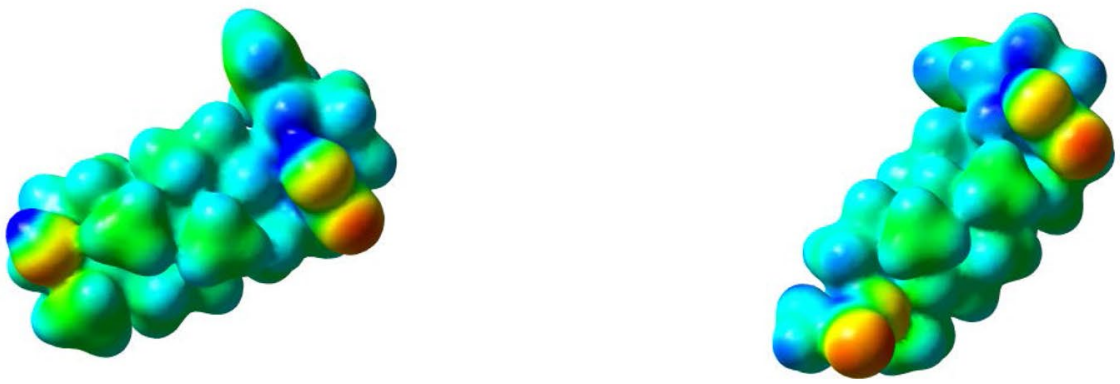

(a) $\mathbf{A}$
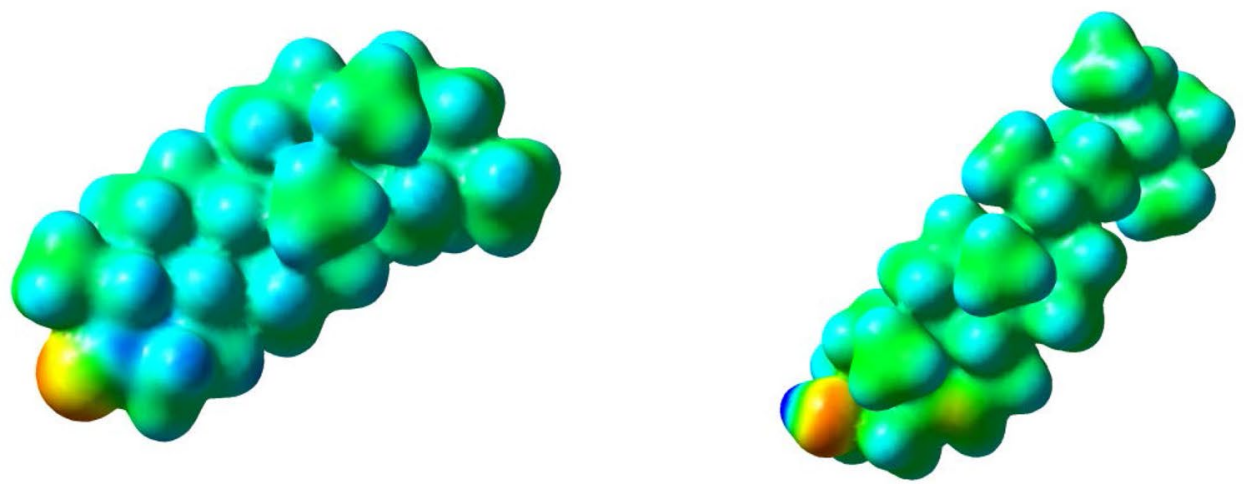

(c) $\mathrm{C}$

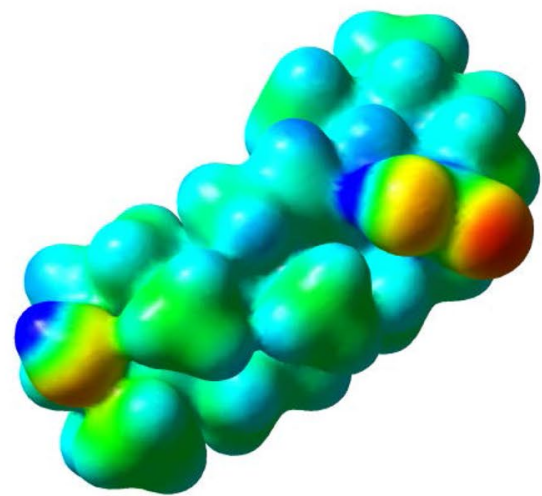

(d) $\mathrm{D}$

(e) $\mathbf{E}$

interactions appear to be reinforced on the carboxyl (A, B, E) than carbonyl (C). The free energies of solvation of $\mathbf{A}-\mathbf{E}$ computed using the continuum solvation models (SMD and $P C M$ ) at M062X/6-31G(d) are shown in the last column of Table 2. Overall, a good agreement was found for the calculated free energies of solvation and computed water binding energies predicting $\mathbf{C}$ and $\mathbf{D}$ to be less stabilized in water solvent.
It is worth noting that implicit solvation model does not take in account $\mathrm{H}$-bond interactions. The optimized geometries of A-D compounds surrounded by up to 89 water molecules computed at PM6 level are given in Fig. 6 . A comparison of the electronic density of states and the vibrational frequencies of $\mathbf{A}\left(\mathrm{H}_{2} \mathrm{O}\right)_{89}, \mathbf{B}\left(\mathrm{H}_{2} \mathrm{O}\right)_{81}, \mathbf{C}\left(\mathrm{H}_{2} \mathrm{O}\right)_{84}$, and $\mathbf{D}\left(\mathrm{H}_{2} \mathrm{O}\right)_{88}$ computed at M062X/6-31G(d) are shown in Fig. 7. All low density contributions are attributed to anti-sickling 
Fig. 5 Optimized geometries of complexes formed by antisickling molecules (A-E) with water (w)

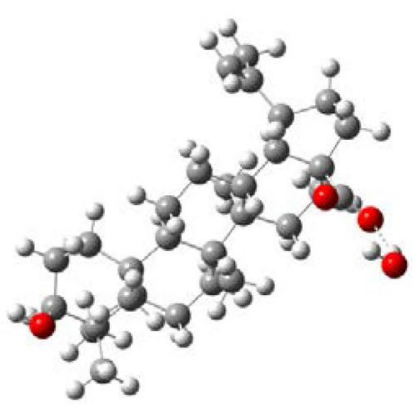

(a) A-w

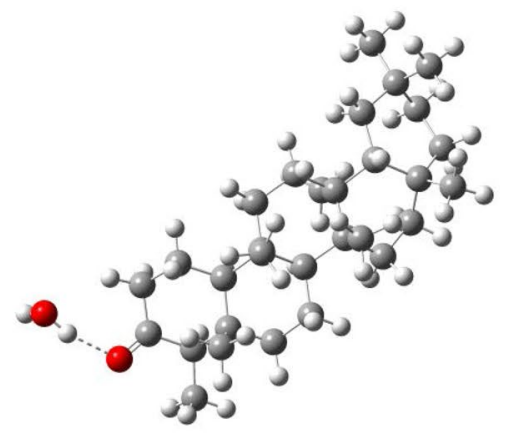

(c) $\mathrm{C}-\mathrm{w}$

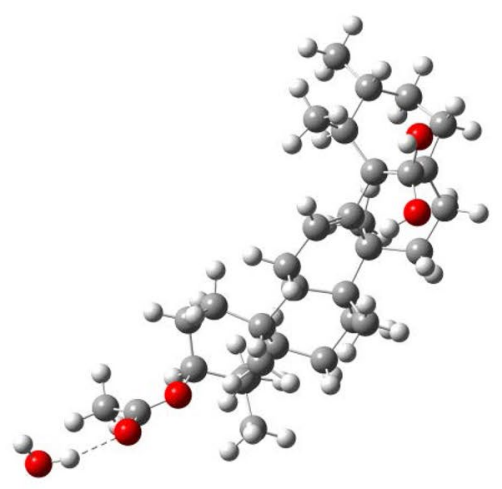

(e) E-w

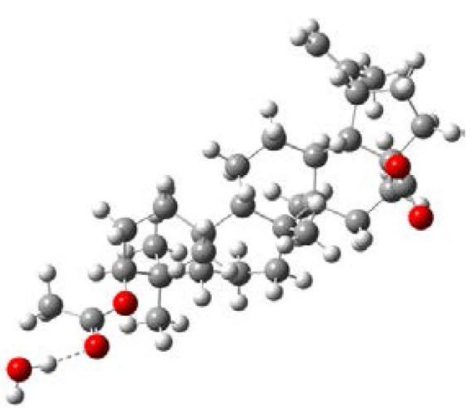

(b) B-w

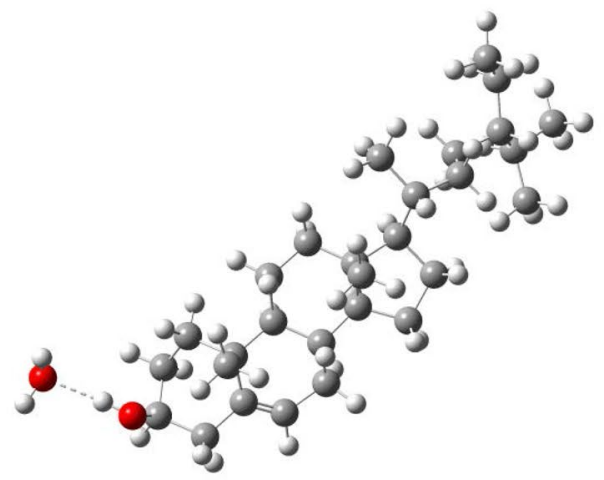

(d) D-W molecular orbitals contributions and give a glimpse on the region in the molecular energy levels where anti-sickling molecules alone contribute. The vibrational analysis of these clusters computed at PM6 is characterized by real frequencies ensuring that the optimized geometries are minima at their potential energy surfaces. The interaction energies between anti-sickling molecules and $\left(\mathrm{H}_{2} \mathrm{O}\right)_{81-89}$ clusters computed at $\mathrm{M} 062 \mathrm{X} / 6-31 \mathrm{G}(d)$ are estimated to be about $-116,-53,-28$, and $-33 \mathrm{kcal} / \mathrm{mol}$ for $\mathbf{A}, \mathbf{B}, \mathbf{C}$, and $\mathbf{D}$, respectively, while the average interaction energy between water molecules in $\left(\mathrm{H}_{2} \mathrm{O}\right)_{81-89}$ clusters is about $-12 \mathrm{kcal} / \mathrm{mol}$ (Table 3). The interaction energy in water dimer is nearly $-4.9 \mathrm{kcal} / \mathrm{mol}[60]$. This difference indicates that $\mathrm{H}$-bonds in water clusters are strengthened due to $\mathrm{H}$-bond cooperativity [61]. The shortest $\mathrm{H}$-bonds formed between A-D and nearest water molecule in $\mathrm{M}\left(\mathrm{H}_{2} \mathrm{O}\right)_{n}$ are in good agreement with the computed interaction energies (Table 3). $\mathbf{A}$ is more stabilized by water solvent than $\mathbf{B}-\mathbf{D}$ in accordance with computed binding energies of $\mathrm{M}\left(\mathrm{H}_{2} \mathrm{O}\right)_{n}$ and $\mathrm{H}$-bonds. The HOMO-LUMO gaps of 
Table 2 Optimized $\mathrm{H}$-bonds in $\AA$, and binding energies in $\mathrm{kcal} / \mathrm{mol}$ between anti-sickling molecules $(\mathbf{A}-\mathbf{E})$ and water molecule computed at B3LYP/6-31G $(d)$ with zero-point vibrational energy correction $(B E+Z P E)$ and without correction of zero-vibrational energy correction (BE) and free energy of solvation (DeltaG in $\mathrm{kcal} / \mathrm{mol}$ ) of anti-sickling molecule $(\mathrm{M})$ in water computing using the SMD implicit solvent model (PCM in parenthesis) at M062X/6-31G $(d)$

\begin{tabular}{lllll}
\hline $\begin{array}{l}\text { Anti-sickling } \\
\text { molecules }(\mathrm{M})\end{array}$ & \multicolumn{2}{l}{$\mathrm{M}\left(\mathrm{H}_{2} \mathrm{O}\right)$} & & \multicolumn{2}{l}{\begin{tabular}{l} 
SMD model of M \\
\cline { 2 - 4 }
\end{tabular}} & $\mathrm{O}-\mathrm{H} \ldots \mathrm{O}$ & $\mathrm{BE}$ & $\mathrm{BE}+\mathrm{ZPE}$ & DeltaG (solv) \\
\hline A & 1.73 & -21.75 & -18.87 & $-9.83(-8.31)$ \\
B & 1.92 & -15.25 & -12.64 & $-13.43(-11.79)$ \\
C & 1.93 & -7.91 & -5.62 & $-0.49(-3.74)$ \\
D & 1.91 & -7.76 & -5.93 & $-0.53(-3.27)$ \\
E & 1.93 & -15.24 & -12.51 & $-7.91(-6.45)$ \\
\hline
\end{tabular}
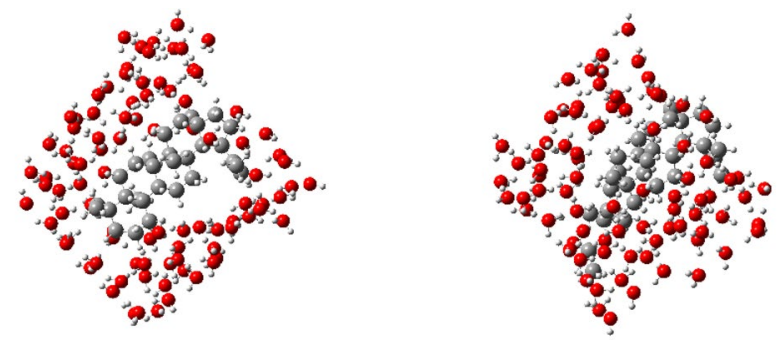

$\mathbf{A}\left(\mathrm{H}_{2} \mathrm{O}\right)_{89}$

$\mathbf{B}\left(\mathrm{H}_{2} \mathrm{O}\right)_{81}$
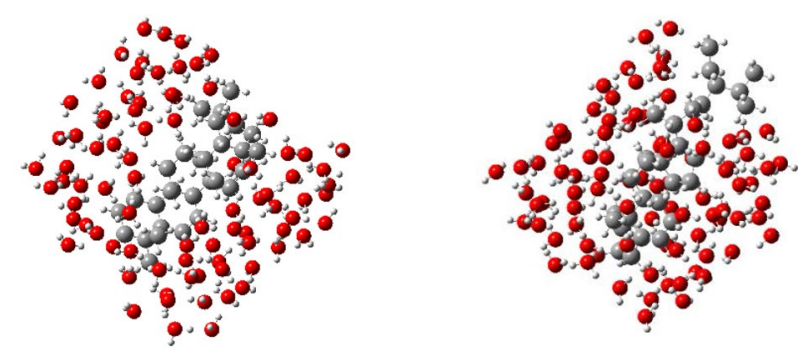

$\mathbf{C}\left(\mathrm{H}_{2} \mathrm{O}\right)_{84}$

$\mathbf{D}\left(\mathrm{H}_{2} \mathrm{O}\right)_{88}$

Fig. 6 PM6 optimized geometries of states of $\mathbf{A}\left(\mathrm{H}_{2} \mathrm{O}\right)_{89}, \mathbf{B}\left(\mathrm{H}_{2} \mathrm{O}\right)_{81}$, $\mathrm{C}\left(\mathrm{H}_{2} \mathrm{O}\right)_{84}$

A-D surrounded by water molecules were computed to examine the effect of the solvent. The water solvent tends to decrease the HOMO-LUMO gap of A-D molecules. D $\left(\mathrm{H}_{2} \mathrm{O}\right)_{88}$ keeps the highest laying $\mathrm{HOMO}$ and the lowest chemical potential and electrophilicity in agreement with gas phase calculations (Tables 1, 3 and Table S1).

\subsection{Molecular docking study on the interaction of A-E and deoxyhemoglobin (2HHB)}

As the sickle cell disease results from the replacement of glutamic acid located in the sixth position of the $\beta$ chain of hemoglobin by valine, further calculations were performed on the anti-sickling plant-isolated terpenes in the hemoglobin environment using the deoxyhemoglobin (entry 2HHB PDB) [39]. Hemoglobin is a tetramer made up of two alpha chains and two beta chains, each containing 141 and 146 amino acid residues, respectively. Each chain carries one heme. The alpha chains contain seven and the beta chains eight helical segments, interrupted by non-helical ones [62]. Hemoglobin $(\mathrm{Hb})$ is the respiratory protein of the red blood cells which carries $\mathrm{O}_{2}$ from the lungs to the tissues and facilitates the return transport of $\mathrm{CO}_{2}$ from the tissues to the lungs. Its understanding is fundamental to understand protein functions.

Docking calculations of $\mathbf{A}-\mathbf{E}$ ligands with $2 \mathrm{HHB}$ as target protein were carried out using SwissDock program [55, 56]. It is known that the prediction of the correct binding mode of ligand into a protein target is still far from being perfect. The potential $\mathbf{A}$ ligand poses are shown in Fig. 8. The great interaction energies for $\mathbf{A}-\mathbf{E}$ ligands were observed in similar zone of $2 \mathrm{HHB}$. The best sites that provide the strongest interactions that might hold the active anti-sickling plant molecules are located in the space between alpha and beta unit. The free binding energies, van der Waals energies, and $\mathrm{H}$-bond distances between $2 \mathrm{HBB}$ and the $\mathbf{A}, \mathbf{B}, \mathbf{C}, \mathbf{D}$, and $\mathbf{E}$ ligands are shown in Table 4. The anti-sickling agent, betulinic acid, denoted as $\mathbf{A}$, shows a greater binding energy $(-9.32 \mathrm{kcal} / \mathrm{mol})$ followed by ursolic acid $(-9.10 \mathrm{kcal} / \mathrm{mol})$ and betulinic acetate $(-8.39 \mathrm{kcal} / \mathrm{mol})$. The friedelan-3-one and $\beta$-sitosterol characterized by the binding energies of $-7.86 \mathrm{kcal} / \mathrm{mol}$ and $-8.15 \mathrm{kcal} / \mathrm{mol}$ were found experimentally least active and non-active [21]. Most of the ligands (A, D, E) are stabilized in $2 \mathrm{HHB}$ protein by hydrogen bond interactions involving $\mathrm{O}-\mathrm{H}$ and $\mathrm{C}=\mathrm{O}$ groups (Table 4, Fig. 9). $\mathbf{A}$ and $\mathbf{E}$ ligands form more hydrogen bonds with $2 \mathrm{HHB}$ that may justify their greater binding energies. Two different dock poses with close free binding energies of -7.86 and $-7.90 \mathrm{kcal} / \mathrm{mol}$ were observed for the friedelan-3-one molecule (Fig. 9i, j). $\mathbf{A}$ and $\mathbf{E}$ ligands form $\mathrm{C}=\mathrm{O}$... H bonds with arginine residue, Arg-104, of 1.921 and $2.780 \AA$ for $\mathbf{A}$ and 2.141 and $2.265 \AA$ for $E$. The hydroxyl group attached to ligand also forms $\mathrm{H}$-bonds with Lys-144 and Tyr-145 of 1.970 and 2.750 for $\mathbf{A}$ and $\mathbf{E}$, respectively. The non-active molecule (D) also has hydroxyl group that forms hydrogen bond of $2.339 \AA$ A length with Val-1 (Table 4, Fig. 9h). In general, the docking calculations of $\mathbf{A}, \mathbf{D}$, and $\mathbf{E}$ suggest a considerable interaction between ligands and the amino acids residues arginine, valine, lysine, and tyrosine. The beta sequences of complexes formed between $2 \mathrm{HHB}$ with the anti-sickling molecule $\mathbf{A}$ were aligned and superimposed with a deoxy-quaternary hemoglobin with liganded beta subunits (1NIH_B PDB entry). The structure comparison reveals that binding sites of inositol hexaphosphate 
Fig. 7 Density of states computed at M062X/6-31G $(d)$ at the left and IR spectra at the right of $\mathbf{A}\left(\mathrm{H}_{2} \mathrm{O}\right)_{89}, \mathbf{B}\left(\mathrm{H}_{2} \mathrm{O}\right)_{81}$, C $\left(\mathrm{H}_{2} \mathrm{O}\right)_{84}$ computed at PM6

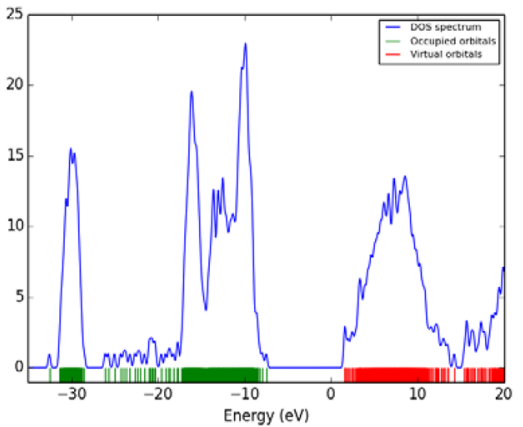

(a) $\mathbf{A}\left(\mathrm{H}_{2} \mathrm{O}\right)_{89}$

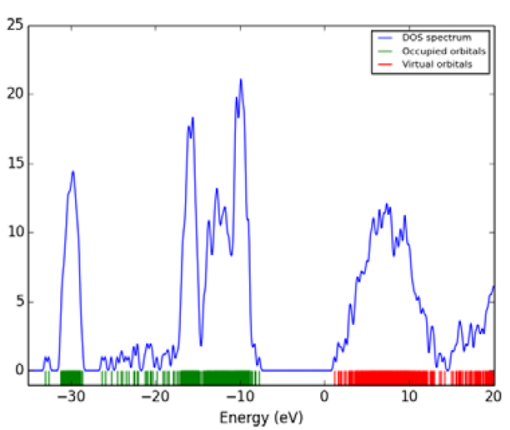

(c) $\mathbf{B}\left(\mathrm{H}_{2} \mathrm{O}\right)_{81}$

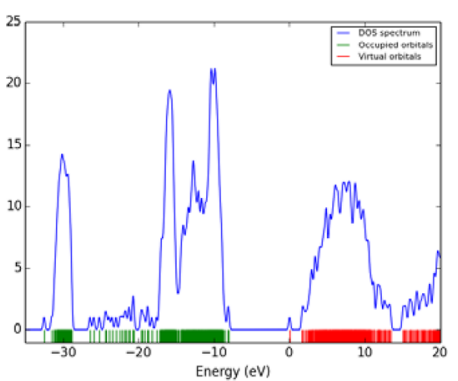

(e) $\mathrm{C}\left(\mathrm{H}_{2} \mathrm{O}\right)_{84}$

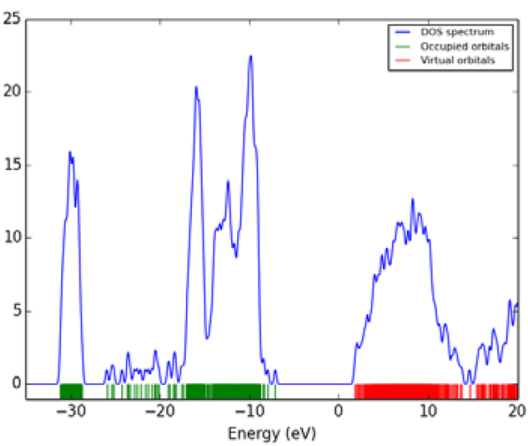

(g) $\mathbf{D}\left(\mathrm{H}_{2} \mathrm{O}\right)_{88}$

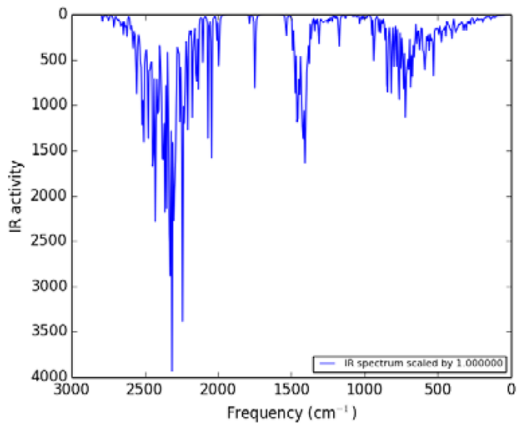

(b) $\mathbf{A}\left(\mathrm{H}_{2} \mathrm{O}\right)_{89}$

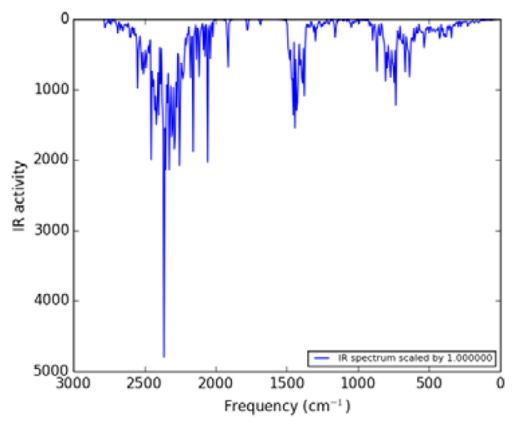

(d) $\mathbf{B}\left(\mathrm{H}_{2} \mathrm{O}\right)_{81}$

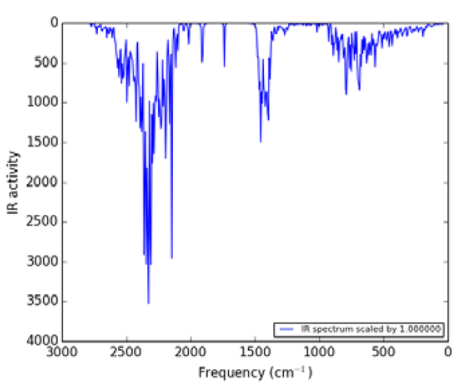

(f) $\mathbf{C}\left(\mathrm{H}_{2} \mathrm{O}\right)_{84}$

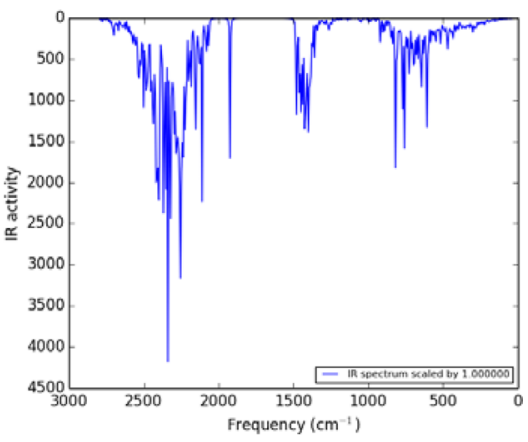

(h) $\mathbf{D}\left(\mathrm{H}_{2} \mathrm{O}\right)_{88}$ 
Table 3 Interaction energies between explicit water cluster $\left(\mathrm{H}_{2} \mathrm{O}\right)_{n}$ and anti-sickling molecule (M) (IE in kcal/mol), average water-water interaction (AIE in $\mathrm{kcal} / \mathrm{mol}$ ), HOMO-LUMO gap energies $(\mathrm{H}-\mathrm{L}$ in

\begin{tabular}{llllllllll}
\hline $\mathrm{M}\left(\mathrm{H}_{2} \mathrm{O}\right)_{n}$ & $n$ & $\mathrm{H}$ & $\mathrm{L}$ & $\mathrm{H}-\mathrm{L}$ & $\mathrm{IE}$ & $\mathrm{AIE}$ & $\mathrm{O} \ldots \mathrm{H}$ & $\mu$ & $\omega$ \\
\hline A & 89 & -7.48 & 1.57 & 9.05 & -116.00 & -11.23 & 1.365 & 2.96 \\
B & 81 & -7.71 & 1.17 & 8.88 & -53.15 & -11.75 & 1.470 & 3.27 \\
C & 84 & -8.05 & 0.04 & 8.09 & -27.71 & -11.61 & 1.891 & 4.00 & 0.48 \\
D & 88 & -7.09 & 1.79 & 8.88 & -33.42 & -12.30 & 1.760 & 2.65 & 0.39 \\
\hline
\end{tabular}

Fig. 8 Potential ligand poses of betulinic acid with $2 \mathrm{HHB}$ and most viable position of ligand with highest full fitness and lowest free binding energy
eV) computed at M062X/6-31G $(d)$, shortest $\mathrm{O} . . . \mathrm{H}$ bond between $\mathrm{M}$ and $\left(\mathrm{H}_{2} \mathrm{O}\right)_{n}$ (in $\AA$ ) computed at PM6

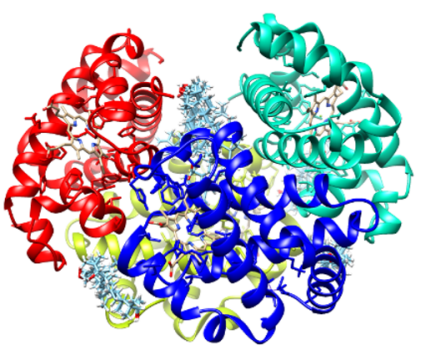

(a) Front side

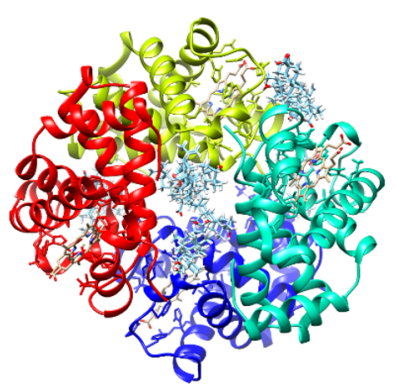

(c) top side

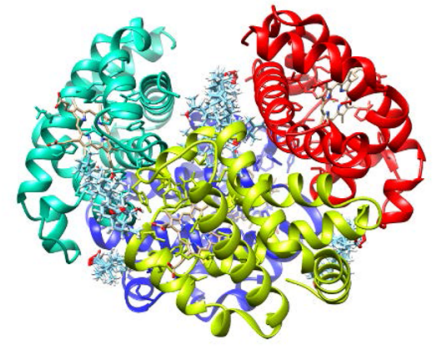

(b) Back side

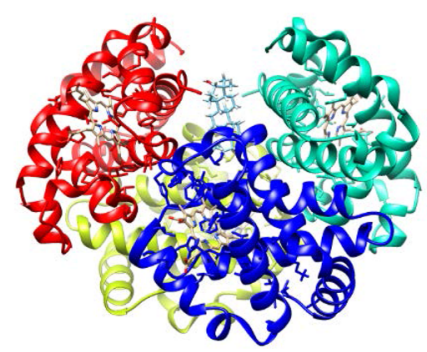

(d) most viable position $(-9.32 \mathrm{kcal} / \mathrm{mol})$
Table 4 Binding free energies in $\mathrm{kcal} / \mathrm{mol}$ and hydrogen bond distances between $2 \mathrm{HHB}$ hemoglobin and $\mathrm{A}-\mathrm{E}$ ligands computed using SwissDock program

\begin{tabular}{|c|c|c|c|c|}
\hline Ligands & $\begin{array}{l}\text { Binding ener- } \\
\text { gies }\end{array}$ & VDW & H-Btype & Type \\
\hline Bet acid & -9.32 & -76.83 & $\begin{array}{l}1.970 \\
1.921 \\
2.780\end{array}$ & $\begin{array}{l}\mathrm{O}-\mathrm{H} . . . \text { Lys }-144 \\
\mathrm{C}=\mathrm{O} \ldots \text {... Arg-104 } \\
\mathrm{C}=\mathrm{O} . . . \text { Arg-104 }\end{array}$ \\
\hline Bet acet & -8.39 & -68.27 & - & - \\
\hline Fried 13-4 & -7.86 & -34.54 & - & - \\
\hline Sist & -8.15 & -39.92 & 2.339 & $\mathrm{H}-\mathrm{O} \ldots \mathrm{Val}-1$ \\
\hline Urs & -9.10 & -69.02 & $\begin{array}{l}2.750 \\
2.141 \\
2.265\end{array}$ & $\begin{array}{l}\mathrm{O}-\mathrm{H} . . . \text { Tyr-145 } \\
\mathrm{C}=\mathrm{O} \ldots \text {...Arg-104 } \\
\mathrm{C}=\mathrm{O} \text {...Arg-104 }\end{array}$ \\
\hline IHP & -25.01 & -629.01 & $\begin{array}{l}1.715 ; 1.905 \\
2.112 \\
1.769,2.065 \\
2.463,2.463\end{array}$ & $\begin{array}{l}\mathrm{P}=\mathrm{O} \ldots \mathrm{H} \text { Val-1 } \\
\mathrm{Hsd}-2 \\
\text { Lys-82 }\end{array}$ \\
\hline
\end{tabular}

ligand (IHP, an allosteric effector) and A-E ligands in $2 \mathrm{HHB}$ are almost different (Fig. 10). According to Lal et al. [63], inositol hexaphosphate (IHP) binds to deoxyhemoglobin and leads to a lowered oxygen affinity, but the manner in which this effector impacts oxygen binding is unclear and may involve changes in structure, dynamics. The docking calculations predict the binding energy between IHP and $2 \mathrm{HHB}$ of $-25.01 \mathrm{kcal} / \mathrm{mol}$ and characterized by seven $\mathrm{P}=\mathrm{O}$... H hydrogen bonds ranging between $1.715-2.463$ $\AA$ involving Val-1, Hsd-2, and Lys- 82 residues. The binding energies of $\mathbf{A}$ and $\mathbf{E}$ with $2 \mathrm{HHB}$ are smaller compared to the binding of the ligand effector IHP with $2 \mathrm{HHB}$, but approach the binding affinity of $\mathbf{A}$ with phospholipase A2 (PL A2) of - $9.81 \mathrm{kcal} / \mathrm{mol}$ calculated by Kan et al. [36].

Betulinic acid (A), betulinic acetate (B), and ursolic acid (E) are the most potent compounds (Table 1). Interestingly, they are more electron donating than $\mathbf{C}$ and $\mathbf{D}$ 
Fig. 9 Most viable docked poses of A-E ligands in $2 \mathrm{HHB}$ and $\mathrm{H}$-bonds distances

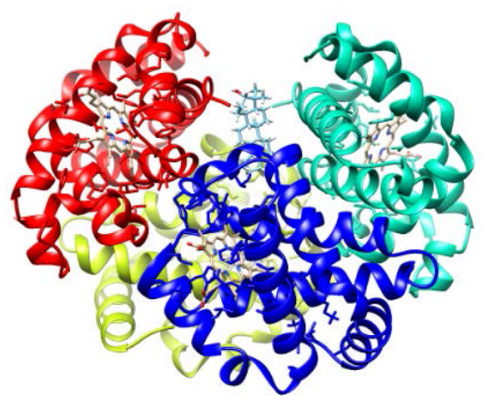

(a) betulinic acid $2 \mathrm{HBB}$

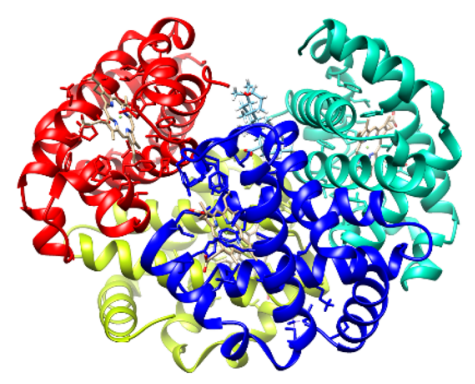

(c) ursolic acid $2 \mathrm{HBB}$

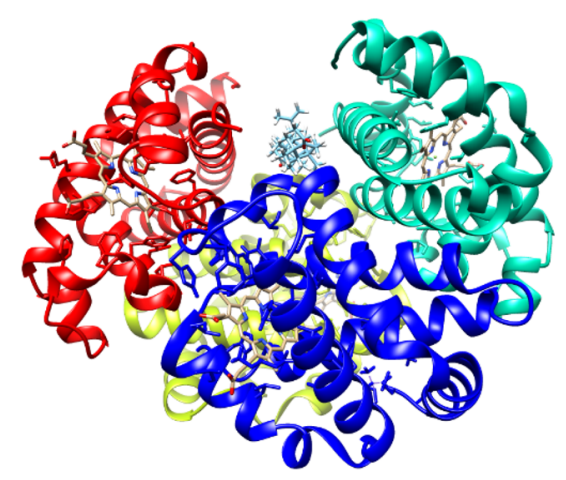

(e) bet-acet $2 \mathrm{hhb}$

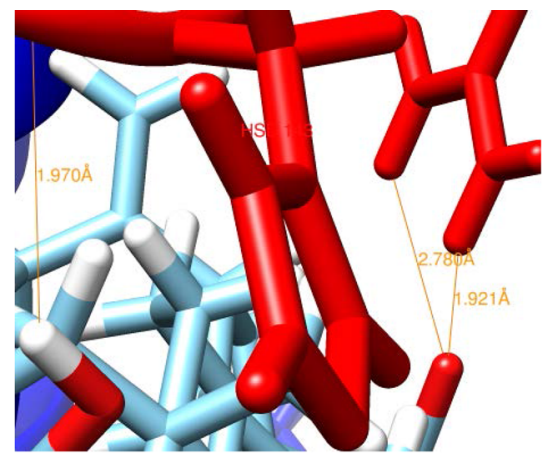

(b) enlarged view of $\mathrm{A}$ in $2 \mathrm{HBB}$

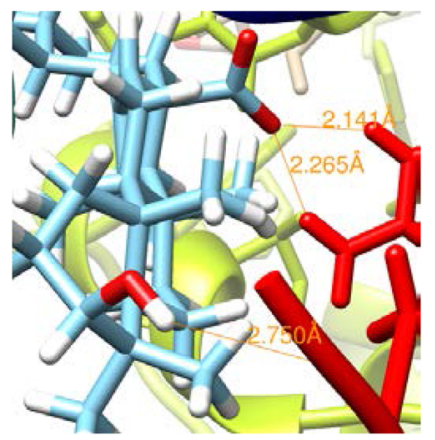

(d) enlarged view of $\mathrm{E}$ in $2 \mathrm{HHB}$

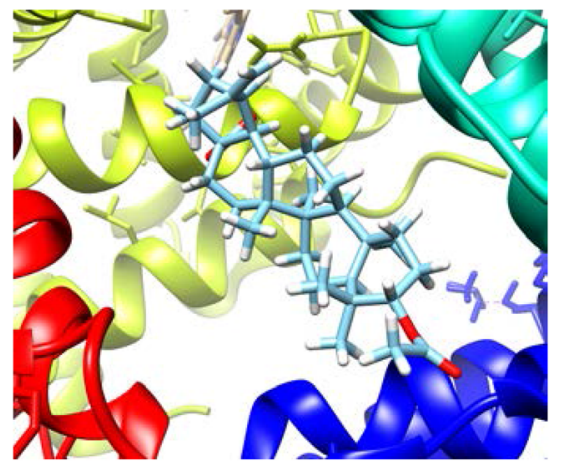

(f) enlarged view of $\mathrm{B}$ in $2 \mathrm{HHB}$ and possess the greatest aqueous stability and binding interactions. The opposite effect was observed with $\mathbf{C}$ and $\mathbf{D}$ which were the least stable in solution and possess the lowest binding energies. This may suggest that A, B, and $\mathbf{E}$ compounds may yield longer-lived prodrugs. Compounds with chemical potential, electron-donating power, electrophilicity, electrophilicity difference, and dipole moment similar to $\mathbf{A}$ such as $\mathbf{B}$ and $\mathbf{E}$ retained their bio-activity. Notably, they all possess the strongest binding interactions with hemoglobin (2HHB) and water. The non-active compound (D) referring to Table 1 possesses the smallest chemical potential, electrophilicity, electrondonating power, and the electrophilicity difference of the series. Since the IC50 of these compounds has not yet been measured, the following correlation was found for binding energies in biological environment.

$\mathrm{BE}=426.83 \mu+435.45 \omega-534.26 \omega^{-}-34.408 \Delta \omega-1.8018 \mathrm{DM}$

Hence, it is evident from this Eq. (13) that the chemical potential, electrophilicity, and electron-donating power have a strong impact on the interactions of betulinic acid (A), betulinic acid acetate (B), friedelan-3-one 
Fig. 9 (continued)

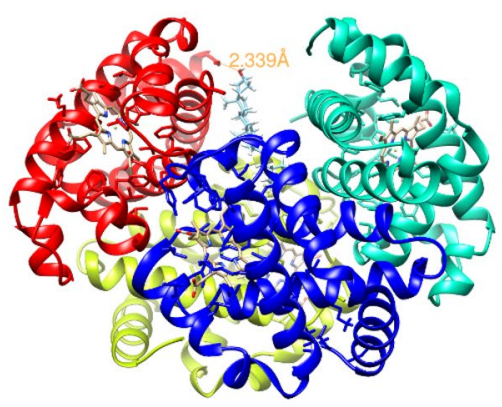

(g) sist_2hhb

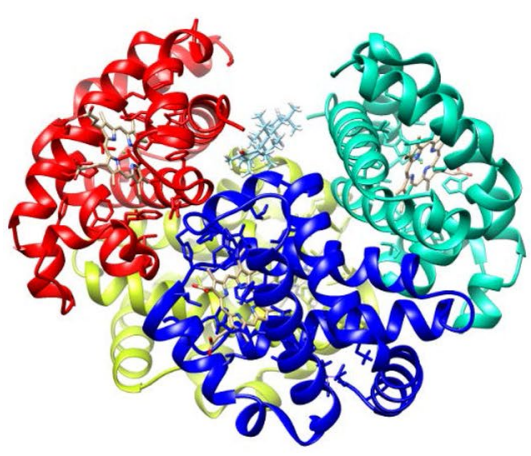

(i) fried $2 \mathrm{hhb}(1)$

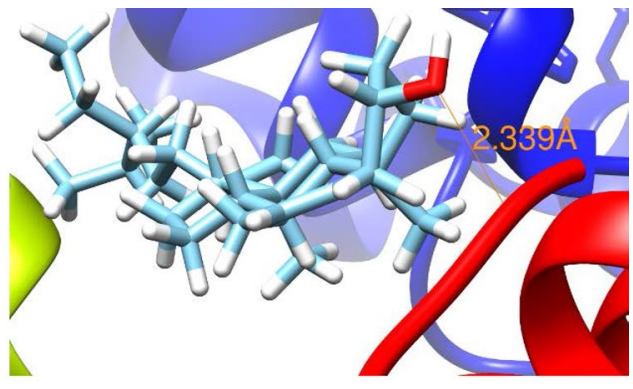

(h) enlarged view of $\mathrm{D}$ in $2 \mathrm{HHB}$

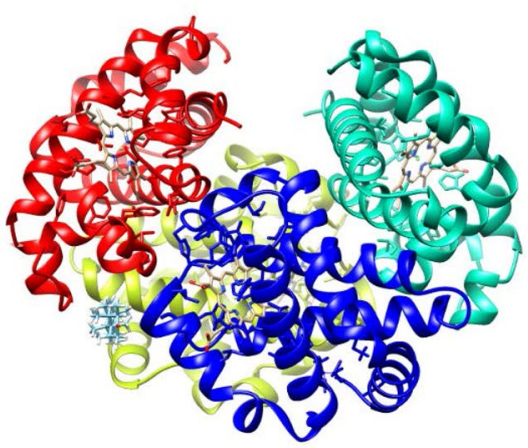

(j) fried_2hhb(2)
(C), $\beta$-sitosterol (D), and ursolic acid (E) molecules with hemoglobin (2HHB).

\section{Conclusion}

Betulinic acid, betulinic acid acetate, friedelan-3-one, and ursolic acid exhibit bioactivity against sickle cell disease. Global reactivity descriptors (e.g., HOMO, chemical potential, hardness, dipole moment, and electrophilicity) and local 3D descriptors (molecular electrostatic potentials, Fukui functions, and dual descriptors) of betulinic acid (A), betulinic acid acetate (B), friedelan-3-one (C), $\beta$-sitosterol (D), and ursolic acid (E) were computed through conceptual density functional theory using B3LYP and M062X functionals with $6-311+G(d, p)$ and 6-31G $(d)$ basis sets in an attempt to understand their structures, stabilities, and bioactivities. The 6-31G $(d)$ basis set tends to underestimate the chemical potential, electron-donating and electron-accepting powers, and dipole moments and overestimate the hardness, homo-lumo gaps, and electrophilicity compared to $6-311+G(d, p)$. The analysis of the computed reactivity descriptors reveals that these terpenes behave as electron donors with preferential active sites located on carbonyl. The computed free energies of solvation of anti-sickling molecules and water interaction energies show that water molecule interacts a bit more strongly with $\mathbf{A}$ than B-E. A molecular docking study with Swisdock program was conducted to explore the binding modes of $\mathbf{A}-\mathbf{E}$ ligands after their optimization and minimization using Gaussian. This analysis predicts that $\mathbf{A}$ and $\mathbf{E}$ interact with deoxyhemoglobin (2HHB) on a common binding site with the amino acid residues Arg104 through $\mathrm{C}=\mathrm{O}$...H(Arg) bond, while B, C, D showed different binding sites. The betulinic acid showed the lowest free binding energy with $2 \mathrm{HHB}$ of $-9.36 \mathrm{kcal} /$ $\mathrm{mol}$ followed by ursolic acid ( $\mathrm{BE}=-9.17 \mathrm{kcal} / \mathrm{mol})$. The former approaches the binding affinity of docked complex between $\mathbf{A}$ and phospholipase A2 (PLA2) of $-9.81 \mathrm{kcal} / \mathrm{mol}$. The binding energies obtained from the protein ligand docking calculations are found to be in good agreement with the ranking of interaction energies of A-E ligands and water calculated used quantum mechanical method. This makes $\mathbf{A}, \mathbf{B}$, and $\mathbf{E}$ molecules an appealing target for anti-sickling activity. However, it is to be noted that these predictions of binding mode of A-E into $2 \mathrm{HHB}$ target hemoglobin protein are far from being perfect. Thus, further experimental studies and evaluation of structure-activity relationship could help 


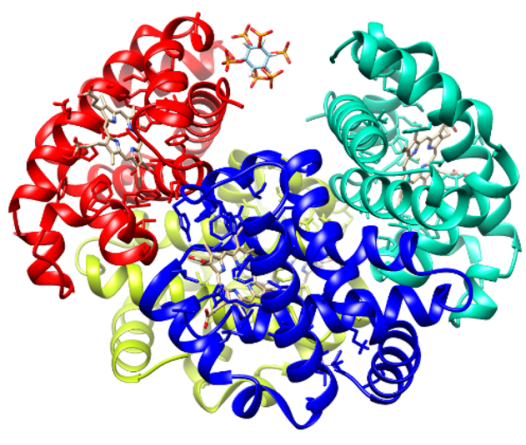

(a) 1nihb liganded

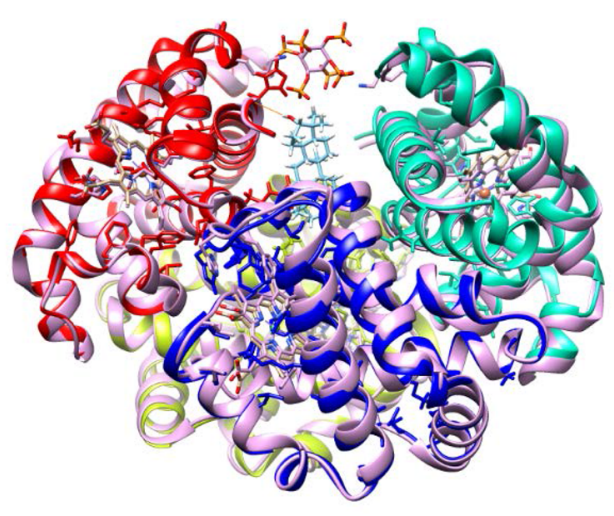

(c) superperposition of betacid $2 \mathrm{hhb}$ and

1nihb liganded

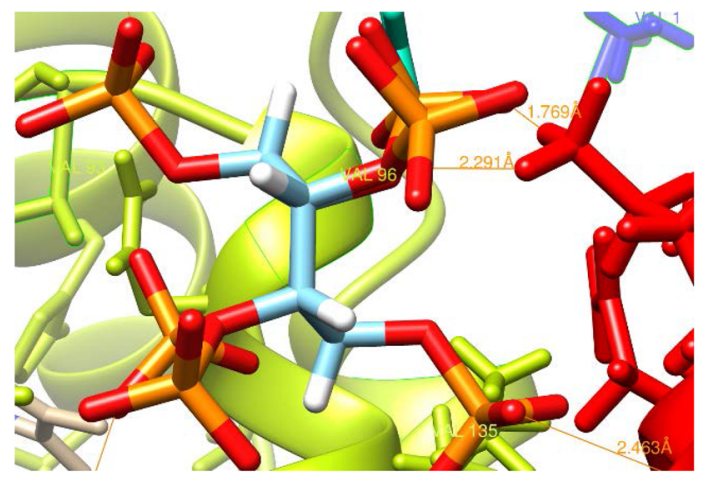

(b) H-bond distances formed by IHP

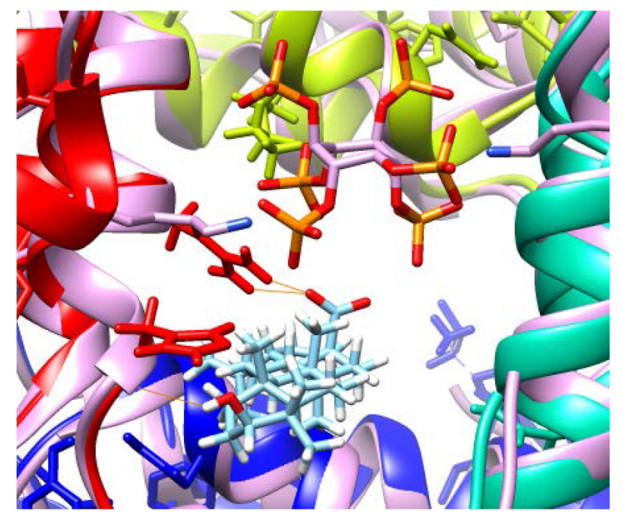

(d) section of betacid $2 \mathrm{hhb}$ and 1 nihb

liganded superimposed

Fig. 10 Structural comparison between 1NIHB liganded with IHP and 2HHB liganded with betulinic acid

in the development of potential anti-sickling molecules, clarifying the correlation between the chemical reactivity indices and the anti-sickling activity.

\begin{abstract}
Acknowledgements The authors gratefully acknowledge and thank Prof. Carol Parish of the University of Richmond (USA) for utilization of her computing resources and Prof Paul Geerlings from VUB for fruitful discussion. DT Mwanagomo thanks the TWAS for the scholarship. One of the authors (Pius T Mpiana) thanks the TWAS and the Swedish International Development Agency (SIDA) for the grant. JT Muya thanks the Korea Research Fellowship program funded by the Ministry of Science and ICT through the National Research Foundation of Korea (NRF-2015H1D3A1062502) for financial support.
\end{abstract}

\section{Compliance with ethical standards}

Conflict of interest The authors declare that they have no competing interest.

\section{References}

1. Hsieh MM, Fitzhugh CD, Tisdale JF (2011) Allogeneic hematopoietic stem cell transplantation for sickle cell disease: the time is now. Blood 118(5):1197-1207

2. Tshilanda DD, Mutwale PK, Onyamboko DVN, Babady PB (2016) Chemical Fingerprint and anti-sickling activity of rosmarinic acid and methanolic extracts from three species of ocimum from DR Congo. J Biosci Med 4:59-68

3. Shenoy S (2013) Hematopoietic stem-cell transplantation for sickle cell disease: current evidence and opinions. Ther Adv Hematol 4(5):335-344

4. Shenoy S (2011) Hematopoietic stem cell transplantation for sickle cell disease: current practice and emerging trends. Hematol Am Soc Hematol 2011:273-279. https://doi. org/10.1182/asheducation-2011.1.273

5. Mpiana PT, Ngbolua KN, Tshibangu STD (2016) Les alicaments et la drépanocytose: une mini-revue. Compt Rend Chim 19(7):884-889 
6. Hulbert ML, Shenoy S (2018) Hematopoietic stem cell transplantation for sickle cell disease: progress and challenges. Pediatr Blood Cancer 65(9):e27263

7. Kassim AA, Sharma D (2017) Hematopoietic stem cell transplantation for sickle cell disease: the changing landscape. Hematol Oncol Stem Cell Ther 10(4):259-266

8. Copelan EA (2006) Hematopoietic stem-cell transplantation. N Engl J Med 354(17):1813-1826

9. Cornelissen JJ, Blaise D (2016) Hematopoietic stem cell transplantation for patients with AML in first complete remission. Blood 127(1):62-70

10. Dedeken L, Le PQ, Azzi N, Brachet C, Heijmans C, Huybrechts S, Devalck C, Malou NM, Ferster A (2011) Hematopoietic stem cell transplantation for sickle cell disease in childhood: a single center experience with 45 patients. Blood 118(21):3103

11. Mpiana PT, Ngbolua KN, Mudogo V, Tshibangu DST, Atibu EK, Kasonga TM, Bokota MT (2010) In vitro effects of anthocyanins extracts from Justicia secunda VAHL on the solubility of hemoglobin S and membrane stability of sickle erythrocytes. Blood Transf 8:248-254

12. Hosoya H, Levine J, Abt P, Henry D, Porter DL, Gill S (2018) Toward dual hematopoietic stem-cell transplantation and solid-organ transplantation for sickle-cell disease. Blood Adv 2(5):575-585

13. Gilman AL, Eckrich MJ, Epstein S, Barnhart C, Cannon M, Fukes T, Hyland M, Shah K, Grochowski D, Champion E, Ivanova A (2017) Alternative donor hematopoietic stem cell transplantation for sickle cell disease. Blood Adv 1(16):1215-1223

14. Mpiana PT, Makelele LK, Oleko RW, Bokota MT, Tshibangu DST, Ngbolua KN, Mbala MB, Atibu EK, Nsimba SM (2010) Antisickling activity of medicinal plants used in the management of sickle cell disease in Tshopo district, D.R.Congo. Aust J Med Herbal 22:132-137

15. Mpiana PT, Mudogo V, Ngbolua KN, Tshibangu DST, Atibu EK (2010) In vitro Antisickling Activity of Anthocyanins Extracts from Morinda lucida Benth (Rubiaceae). In: Gupta VK, Singh GD (eds) Medicinal plants: phytochemistry, pharmacology and therapeutics. Daya Publishing House, New Delhi, pp 330-337

16. Mossi AJ, Mazutti M, Paroul N, Corazza ML, Dariva C, Cansian RL, Oliveira JV (2009) Chemical variation of tannins and triterpenes in Brazilian populations of Maytenus ilicifolia Mart. Ex Reiss. Braz J Biol 69(2):339-345

17. Mpiana PT, Ngbolua KN, Mudogo V, Tshibangu DST, Atibu EK, Mbala BM, Kahumba B, Bokota MT, Makelele LT (2012) The potential effectiveness of medicinal plants used for the treatment of sickle cell disease in the Democratic Republic of Congo folk medicine: a review. In: Gupta VK, Singh GD (eds) Traditional and folk herbal medicine, vol 1. Daya Publishng House, New Delhi, pp 1-11

18. Tshilanda DD, Onyamboko DV, Tshibangu DST, Ngbolua KN, Tsalu PV, Mpiana PT (2015) In vitro antioxidant activity of essential oil and polar and non-polar extracts of Ocimum canum from Mbuji-Mayi (DR Congo). J Adv Med Life Sci. https://doi. org/10.15297/jals.v3i3.04

19. Mpiana PT, Misakabu FM, Tshibangu DST, Ngbolua KN, Mwanangombo DT (2014) Antisickling activity and membrane stabilization effect of anthocyanins extracts from Adansonia digitata L. barks on sickle blood cells. Int Blood Res Rev 2(5):198-212

20. Ngbolua KN, Bishola TT, Mpiana PT, Mudogo V, Tshibangu DST, Ngombe KN, Ekutsu EG, Tshilanda DD, Gbolo ZB, Mwanangombo DT, Fatiany PR, Baholy B (2014) Ethno-botanical survey in vitro antisickling and free radical scavenging activities of Garcinia punctata Oliv. (Clusiaceae). J Adv Bot Zool e1(2):1-7

21. Tshibangu DST (2012) Phytochemical and anti-drepanocytosis studies of Cajanus cajan, Callistemon viminalis, Melaleuca bracteata Var. revolution gold and syzyguum guineense. Master
Thesis, Faculty of Science and Agriculture, University of Kwazulu Natal, Republic of South Africa

22. Mpiana PT, Ngbolua KN, Bokota MT, Kasonga TK, Atibu EK, Mudogo V (2009) Antisickling activity of Justicia secunda Vahl. In: Drug discovery from African rain forest, the 13th symposium of the natural product research Network for Eastern and Central Africa, University of Kinshasa, Democratic Republic of Congo 10-14 August 2009 p 21 (SL-4)

23. Ayaz M, Junaid M, Ullah F, Subhan F, Sadiq A, Ali G, Ovais M, Shahid M, Ahmad A, Wadood A, El-Shazly M, Ahmad N, Ahmad $S$ (2017) Anti-Alzheimer's studies on $\beta$-sitosterol isolated from polygonum hydropiper L. Front Pharmacol 8:697

24. Babalola IT, Shode FO, Adelakun EA, Opoku AR, Mosa RA (2013) Platelet-aggregation inhibitory activity of oleanolic acid, ursolic acid, betulinic acid, and maslinic acid. J Pharmcogn Phytochem 1(6):54

25. Igoli OJ, Gray IA (2008) Friedelanone and other triterpenoids from Hymenocardia acida. Int J Phys Sci 3:156-158

26. Ichiko CO, Terrumun AT, Igoli JO, Vershima A (2016) In vitro antimicrobial properties of friedelan-3-one from Pterocarpus santalinoides L'Herit, ex Dc. Afr J Biotechnol 15(14):531

27. Chowdhury AR, Mandal S, Mittra B, Sharma S, Mukhopadhyay S, Majumder HK (2002) Betulinic acid, a potent inhibitor of eukaryotic topoisomerase I: identification of the inhibitory step, the major functional group responsible and development of more potent derivatives. Med Sci Monit 8(7):BR254-BR265

28. Zuco V, Supino R, Righetti SC, Cleris L, Marchesi E, GambacortiPasserini C, Formelli F (2002) Selective cytotoxicity of betulinic acid on tumor cell lines, but not on normal cells. Cancer Lett 175(1):17-25

29. Thurnher D, Turhani D, Pelzmann M, Wannemacher B, Knerer B, Formanek M, Wacheck V, Selzer E (2003) Betulinic acid: a new cytotoxic compound against malignant head and neck cancer cells. Head Neck 25(9):732-740

30. Yogeeswari P, Dharmarajan S (2005) Betulinic acid and its derivatives: a review on their biological properties. Curr Med Chem 12(6):657-666

31. https://patents.google.com/patent/WO2011064710A1

32. Tshilanda DD, Onyamboko DNV, Babady-Bila P, Ngbolua KN, Tshibangu DST, Dibwe EF, Mpiana PT (2015) Anti-sickling Activity of ursolic acid isolated from the leaves of Ocimum gratissimum L. (Lamiaceae). Nat Prod Bioprospect 5:215-221

33. Tshibangu DST, Shode FO, Koorbanally N, Mudogo V, Mpiana PT, Ngbolua KN (2011) Anti-sickling triterpenoids from Callistemon Viminalis, Melaleuca Bracteata Var. revolution gold Syzygium Guineense and Syzygium Cordatum. In: African rain forests as source of drugs, the 14th NAPRECA symposium and AAMPS ethno-veterinary medicine symposium 8 August 2011. International Centre For Insect Physiology and Ecology (ICIPE): Kasarani, Nairobi, Kenya, pp 296-300 (YS 27)

34. Swift $R$, Abdulmalik $O$, Chen $Q$, Asakura $T$, Gustafson $K$, Simon JE, Zaman V, Quiusky KA, Hassell KL, Shapira I, Sidhu G, JamesGoulbourne T, Carrington K, Muthu J, Gillette PN (2016) SCD101: a new anti-sickling drug reduces pain and fatigue and improves red blood cell shape in peripheral blood of patients with sickle cell disease. Blood 128:121

35. Malleda C, Ahalawat N, Gokara M, Subramanyam R (2012) Molecular dynamics simulation studies of betulinic acid with human serum albumin. J Mol Model 18:2589-2597

36. Khan MF, Nahar N, Rashid RB, Chowdhury A, Rashid MA (2018) Computational investigations of physicochemical, pharmacokinetic, toxicological properties and molecular docking of betulinic acid, a constituent of Corypha taliera (Roxb) with Phospholipase A2 (PLA2). BMC Complement Altern Med $18: 48$ 
37. Geerling P, De Proft F (2008) Conceptual DFT: the chemical relevance of higher response functions. Phys Chem Chem Phys 10:3028-3042

38. Geerling P, De Proft F, Langenaeker W (2003) Conceptual density functional theory. Chem Rev 103:1793-1874

39. Fermi G, Perutz MF, Shaanan B, Fourme R (1984) The crystal structure of human deoxyhaemoglobin at $1.74 \AA$ A resolution. J Mol Biol 175:159-174

40. Parr RG, Yang W (1989) Density functional theory of atoms and molecules. Oxford University Press, New York

41. Zhao Y, Truhlar DG (2008) The M06 suite of density functionals for main group thermochemistry, thermochemical kinetics, noncovalent interactions, excited states, and transition elements: two new functionals and systematic testing of four M06-class functionals and 12 other functionals. Theor Chem Acc 120:215-241

42. Dunning TH Jr. (1989) Gaussian basis sets for use in correlated molecular calculations. I. The atoms boron through neon and hydrogen. J Chem Phys 90:1007

43. Marenich AV, Cramer CJ, Truhlar DG (2009) Universal solvation model based on solute electron density and on a continuum model of the solvent defined by the bulk dielectric constant and atomic surface tensions. J Phys Chem B 113(18):6378-6396

44. Mennucci B, Cancès E, Tomasi J (1997) Evaluation of solvent effects in isotropic and anisotropic dielectrics and in ionic solutions with a unified integral equation method: theoretical bases, computational implementation, and numerical applications. J Phys Chem B 101(49):10506-10517

45. Frisch M, Trucks GW, Schlegel HB, Scuseria GE, Robb MA, Cheeseman JR, Scalmani G, Barone V, Petersson GA, Nakatsuji H, Li X, Caricato M, Marenich AV, Bloino J, Janesko BG, Gomperts R, Mennucci B, Hratchian HP, Ortiz JV, Izmaylov AF, Sonnenberg JL, Williams-Young D, Ding F, Lipparini F, Egidi F, Goings J, Peng B, Petrone A, Henderson T, Ranasinghe D, Zakrzewski VG, Gao J, Rega N, Zheng G, Liang W, Hada M, Ehara M, Toyota K, Fukuda $\mathrm{R}$, Hasegawa J, Ishida M, Nakajima T, Honda, Kitao O, Nakai $\mathrm{H}_{\text {, }}$ Vreven T, Throssell K, Montgomery JA Jr, Peralta JE, OgliaroYF, Bearpark MJ, Heyd JJ, Brothers EN, Kudin KN, Staroverov VN, Keith TA, Kobayashi R, Normand J, Raghavachari K, Rendell AP, Burant JC, lyengar SS, Tomasi J, Cossi M, Millam JM, Klene M, Adamo C, Cammi R, Ochterski JW, Martin RL, Morokuma K, Farkas O, Foresman JB, Fox DJ (2016) Gaussian, Inc., Wallingford CT

46. Gazquez JL, Cedillo A, Vela A (2007) Electrodonating and electroaccepting powers. J Phys Chem A 111(10):1966-1970

47. Chattaraj PK, Chakraborty A, Giri S (2009) Net electrophilicity. J Phys Chem A 113(37):10068-10074
48. Kasende OE, Muya JT, Broeckaert L, Maes G, Geerlings P (2012) Theoretical study of the regioselectivity of the interaction of 3-methyl-4-pyrimidone and 1-methyl-2-pyrimidone with lewis acids. J Phys Chem A 116:8008

49. Glossman-Mitnik D (2013) A comparison of the chemical reactivity of naringenin calculated with the M06 family of density functionals. Chem Cent J 7:155

50. Martinez-Araya Jl (2019) The importance of diffuse functions in basis sets to produce reliable 3D pictures of dual descriptor. Chem Phys Lett 724:29-34

51. Dennington R, Keith T, Millan J (2009) GaussView, Version 5. Semichem. Inc., Shawnee Mission

52. Chemdraw Pro, Cambridge soft corporation. Version 8.0 April 23, 2003. http://www.cambridgesoft.com

53. Martins JC, Willem R, Biesemans M (1999) A comparative investigation of the consistent valence and extensible systematic force fields. A case study on the conformation of erythromycin A in benzene. J Chem Soc Perkin Trans 2:1513-1520

54. http://www.vegazz.net

55. Grosdidier A, Zoete V, Michielin O (2011) SwissDock, a proteinsmall molecule docking web service based on EADock DSS. Nucleic Acids Res 39:W270-W277

56. Grosdidier A, Zoete V, Michielin O (2011) Fast docking using the CHARMM force field with EADock DSS. J Comput Chem 32:2149-2159

57. Ren X, Shi Y-S, Liu B, Zhang L-H, Peng Y-B, Zeng R (2018) Novel consensus docking strategy to improve ligand pose prediction. J Chem Inf Model 58:1662-1668

58. http://www.cgl.ucsf.edu/chimera

59. Judy Chang CMS, Kan Yuet Wai, Sc MBD (1982) A sensitive new prenatal test for sickle-cell anemia. N Engl J Med 307:30

60. Feyereisen MW, Feller D, Dixon DA (1996) Hydrogen bond energy of the water dimer. J Phys Chem 100(8):2993-2997

61. Muzomwe M, Muya JT, Hoeil C, Kasende OE (2018) Theoretical study on coordination of methanol clusters to 3-methyl-4-pyrimidone. Struct Chem 29:1-8

62. Perutz MF, Fermi G, Luisi B (1987) Stereochemistry of cooperative mechanisms in hemoglobin. Acc Chem Res 20:309

63. Lal J, Maccarini M, Fouquet P, Ho NT, Ho C, Makowski L (2017) Modulation of hemoglobin dynamics by an allosteric effector. Protein Sci 26:505

Publisher's Note Springer Nature remains neutral with regard to jurisdictional claims in published maps and institutional affiliations. 